\title{
Glucose metabolism reflects local atrophy and tau pathology in symptomatic Alzheimer's disease
}

\author{
Amelia Strom ${ }^{1}$, Leonardo Iaccarino ${ }^{1}$, Lauren Edwards ${ }^{1}$, Orit H. Lesman-Segev ${ }^{1,2}$, David N. Soleimani- \\ Meigooni $^{1}$, Julie Pham ${ }^{1}$, Suzanne L. Baker ${ }^{4}$, Susan Landau ${ }^{3}$, William J. Jagust ${ }^{3,4}$, Bruce L. Miller ${ }^{1}$, \\ Howard J. Rosen ${ }^{1}$, Maria Luisa Gorno-Tempini ${ }^{1}$, Gil D. Rabinovici ${ }^{13,4,5}$, Renaud La Joie ${ }^{1}$, for the \\ Alzheimer's Disease Neuroimaging Initiative*
}

1 Memory and Aging Center, Department of Neurology, Weill Institute for Neurosciences, University of California, San Francisco, San Francisco, CA, United States

2 Department of Diagnostic Imaging, Sheba Medical Center, Tel Hashomer, Ramat Gan, Israel

3 Helen Wills Neuroscience Institute, University of California, Berkeley, Berkeley, CA, United States

4 Molecular Biophysics and Integrated Bioimaging, Lawrence Berkeley National Laboratory, Berkeley, CA, United States

5 Department of Radiology and Biomedical Imaging, University of California, San Francisco, San Francisco, CA, United States

\section{Abstract}

Posterior cortical hypometabolism measured with $\left[{ }^{18} \mathrm{~F}\right]$-Fluorodeoxyglucose (FDG)-PET is a wellknown marker of Alzheimer's disease-associated neurodegeneration, but its associations with underlying neuropathological processes are unclear. We assessed the relative contributions of three potential mechanisms causing hypometabolism in the retrosplenial and inferior parietal cortices: local molecular (amyloid and tau) pathology and atrophy, distant factors including contributions from the degenerating medial temporal lobe or molecular pathology in functionally connected regions, and the presence of the apolipoprotein $\mathrm{E}(A P O E) \varepsilon 4$ allele. Two hundred and thirty-two amyloid-positive cognitively impaired patients from two independent cohorts (University of California, San Francisco, UCSF, and Alzheimer's Disease Neuroimaging Initiative, ADNI) underwent MRI and PET with FDG, amyloid-PET using $\left[{ }^{11} \mathrm{C}\right]-$ Pittsburgh Compound $\mathrm{B}$, $\left[{ }^{18} \mathrm{~F}\right]-$ Florbetapir, or $\left[{ }^{18} \mathrm{~F}\right]$-Florbetaben, and $\left[{ }^{18} \mathrm{~F}\right]$-Flortaucipir tau-PET within one year. Standard uptake value ratios (SUVR) were calculated using tracer-specific reference regions. Brain regions were defined in native space using FreeSurfer. Regression analyses were run within cohorts to identify variables associated with retrosplenial or inferior parietal FDG SUVR. On average, ADNI patients were older and had less severe cognitive impairment than UCSF patients. Regional patterns of hypometabolism were similar between cohorts, though there were cohort differences in regional gray matter atrophy. Local cortical thickness and tau-PET (but not amyloid-PET) were independently associated with both retrosplenial and inferior parietal FDG SUVR $\left(\Delta R^{2}=.09\right.$ to $.21)$ across cohorts in models that also included age and disease severity (local model). Including medial temporal lobe volume improved the retrosplenial FDG model in ADNI $\left(\Delta R^{2}=.04, p=\right.$ $.008)$ but not UCSF $\left(\Delta R^{2}<.01, p=.52\right)$, and did not improve the inferior parietal models $\left(\Delta R^{2} \mathrm{~s}<\right.$ $.01, p \mathrm{~s}>.37)$. Interaction analyses revealed that medial temporal volume was more strongly 
associated with retrosplenial FDG SUVR at earlier disease stages $(p=.06$ in UCSF, $p=.046$ in ADNI). Models including molecular pathology in functionally connected regions, defined based on task-free functional MRI data from the Neurosynth database, or $A P O E \varepsilon 4$ did not outperform local models. Overall, hypometabolism in cognitively impaired patients primarily reflected local atrophy and tau pathology, with an added contribution of medial temporal lobe degeneration at earlier disease stages. Our data did not support hypotheses of a detrimental effect of pathology in connected regions or the presence of the $A P O E \& 4$ allele in impaired participants. FDG-PET reflects structural neurodegeneration and tau, but not amyloid, pathology at symptomatic stages of Alzheimer's disease.

Correspondence to: Renaud La Joie

675 Nelson Rising Lane, Suite 190

San Francisco, California 94158

renaud.lajoie@ucsf.edu

* Data used in the preparation of this article were obtained from the Alzheimer's Disease Neuroimaging Initiative (ADNI) database (adni.loni.usc.edu). As such, the investigators within the ADNI contributed to the design and implementation of ADNI and/or provided data but did not participate in the analysis or writing of this report. A complete listing of ADNI investigators can be found at: http://adni.loni.usc.edu/wpcontent/uploads/how_to_apply/ADNI_Acknowledgement_List.pdf

Running title: Metabolism PET in Alzheimer's disease

Keywords: hypometabolism; Alzheimer's disease; PET; tau; amyloid

Abbreviations: $A P O E \quad \varepsilon 4=$ apolipoprotein $\mathrm{E} \quad \varepsilon 4$; $\mathrm{FBP}=\left[{ }^{18} \mathrm{~F}\right]$-Florbetapir; $\mathrm{FDG}=\left[{ }^{18} \mathrm{~F}\right]-$ Fluorodeoxyglucose; FTP $=\left[{ }^{18} \mathrm{~F}\right]$-Flortaucipir; IP $=$ inferior parietal lobe; $\mathrm{MTL}=$ medial temporal lobe; $\mathrm{PIB}={ }^{11} \mathrm{C}$-Pittsburgh compound-B; RSC $=$ retrosplenial cortex; SUVR = standard uptake value ratio

\section{Introduction}

Alzheimer's disease is defined as the pathological accumulation of $\beta$-amyloid plaques and neurofibrillary tau tangles in the brain, which are thought to induce neurodegeneration and cognitive decline. ${ }^{1}$ FDG-PET is a marker of glucose metabolism and is believed to largely reflect neuronal and synaptic activity. ${ }^{2}$ Patients with Alzheimer's disease frequently exhibit a pattern of temporo-parietal hypometabolism on FDG-PET indicating neurodegeneration. ${ }^{3-7}$ Regional patterns of decreased FDG-PET correlate with cognitive and functional impairment ${ }^{8-12}$ and are detectable early in the disease course, even before clinical symptoms. ${ }^{13,14}$ There are multiple mechanisms, perhaps coexisting, that could cause brain glucose hypometabolism (Figure 1A).

First, molecular pathology (amyloid and tau) and degeneration are associated with hypometabolism within a region (local). Lower brain volume consistently correlates locally with decreased FDG-PET. ${ }^{5,15-18}$ This association may be partially explained by increased partial volume effects, where the limited spatial resolution of PET underestimates local radiotracer retention 
especially in the setting of severe atrophy, ${ }^{19,20}$ though partial volume correction does not remove this association. ${ }^{15}$ However, regional hypometabolism in Alzheimer's disease exceeds what is expected from, and does not perfectly overlap with, atrophy. ${ }^{15,21,22}$ Local tau pathology may partially explain this discrepancy in pattern because tau-PET is related to both structural MRI and FDG-PET measures, though more so to FDG-PET. ${ }^{18,23,24}$ Tau-PET patterns consistently overlap with decreased FDG-PET in preclinical and clinical populations. ${ }^{4,22,25-27}$ Some studies have demonstrated a local correlation between amyloid-PET and FDG-PET as well, ${ }^{28-30}$ but others have found no such association. ${ }^{5,31-35}$

Second, regional hypometabolism can be related to abnormalities occurring in distant regions. For example, FDG-PET can be decreased in regions that are physically distant from but downstream of a structural or pathological lesion. ${ }^{36,37}$ A lesion to the rhinal cortex in primates results in reduced glucose metabolism in many remote brain regions, including parietal, frontal, occipital, and cingulate cortices. ${ }^{38}$ Similarly, in human imaging studies of patients with Alzheimer's dementia, MTL atrophy is related to reduced FDG-PET in the retrosplenial cortex (RSC), perhaps mediated by the disruption of the cingulum bundle. ${ }^{28,35,39}$ Molecular pathology may also influence neurodegeneration remotely via network connections, with supporting evidence for this phenomenon having been observed with tau- and amyloid-PET. ${ }^{24,40,41}$ Notably, Pascoal et al. ${ }^{34}$ found that hypometabolism was not related to local amyloid-PET signal, but was associated with amyloid-PET uptake in functionally connected regions.

Third, the $A P O E \& 4$ allele may itself be associated with reduced metabolism in Alzheimer's disease regions, even in young adults or older adults without amyloid pathology, perhaps as an endophenotype. ${ }^{42-46}$ In symptomatic stages of Alzheimer's disease, findings are more conflicting with some studies suggesting that $A P O E \varepsilon 4$ is associated with a greater decrease in metabolism in Alzheimer's disease regions, ${ }^{47,48}$ while others find no such association. ${ }^{30,31,49}$

Previous findings about determinants of Alzheimer's disease-related hypometabolism may be discrepant due to small samples, the inclusion of amyloid-positive and amyloid-negative patients, or the inclusion of both impaired and unimpaired participants. The present study investigates these potential determinants in two independent samples of amyloid-positive, clinically impaired patients (total $N=232$ ) to understand their relative contributions to hypometabolism in Alzheimer's disease. An understanding of these relationships is important to improve the interpretation of FDG-PET in both research studies and clinical contexts, where FDG-PET is commonly used.

We focused on three hypotheses formulated based on available literature: 1) local contributions from atrophy and molecular pathology, 2) distant effects from either the degenerating MTL (2a) or molecular pathology in functionally connected regions (2b), and 3 ) the presence of the $A P O E$ $\varepsilon 4$ allele (Figure 1). To test these hypotheses, we focused on two regions that display consistently salient hypometabolism on FDG-PET in Alzheimer's disease patients: the posterior cingulate / RSC and inferior parietal (IP) lobe..$^{3,6,7,50}$ We performed analyses in amyloid-positive, cognitively 
impaired patients with Alzheimer's disease from two complementary cohorts covering a range of ages, clinical criteria, and disease severity to strengthen the generalizability of our findings and to potentially understand some of the conflicting results in the existing literature.

We hypothesized that local atrophy, local tau pathology, MTL volume, and molecular pathology in connected regions would be associated with Alzheimer's disease hypometabolism, as these relationships have been observed at symptomatic stages. We expected that MTL volume would be specifically associated with decreased FDG-PET in the RSC but not IP due to its robust structural connections with the RSC. ${ }^{51}$ However, we did not expect $A P O E \varepsilon 4$ to play a role, as its effect has most consistently been observed in preclinical stages. ${ }^{45}$

\section{Materials and methods}

\section{Participants}

Two hundred and thirty-two cognitively impaired individuals were retrospectively included from two independent cohorts. Selection criteria included i) a diagnosis of Mild Cognitive Impairment or dementia due to Alzheimer's disease based on clinical information, ${ }^{52,53}$ ii) available MRI and PET with FDG, an amyloid tracer, and $\left[{ }^{18} \mathrm{~F}\right]$-Flortaucipir (FTP) within 1 year, and iii) amyloidPET positivity.

The first cohort consisted of 85 patients from the UCSF Alzheimer's Disease Research Center. Exclusion criteria for UCSF patients included a history of repetitive head trauma consistent with possible traumatic encephalopathy syndrome. ${ }^{54}$ Twenty-nine patients met additional criteria for specific variants of Alzheimer's disease: logopenic variant of primary progressive aphasia $(n=12)$ and posterior cortical atrophy $(\mathrm{n}=17)$. Amyloid-PET positivity was determined by both visual read by an expert neurologist and an SUVR quantitative threshold (composite score $>1.21$ ) of PET with $\left[{ }^{11} \mathrm{C}\right]$-Pittsburgh Compound B (PIB). ${ }^{55}$

The second cohort consisted of 147 patients from the ADNI study (adni.loni.usc.edu). We included all available ADNI cases with a clinical diagnosis of Mild Cognitive Impairment (early or late) or Alzheimer's disease (dementia) within 1 year of the imaging studies. Amyloid-PET positivity was determined via quantification using tracer-specific quantitative thresholds (see www.adniinfo.org). The ADNI was launched in 2003 as a public-private partnership, led by Principal Investigator Michael W. Weiner, MD. The primary goal of ADNI has been to test whether serial MRI, PET, other biological markers, and clinical and neuropsychological assessment can be combined to measure the progression of Mild Cognitive Impairment and early Alzheimer's disease. For up-to-date information, see www.adni-info.org.

Ethical approval for the present study was given by the University of California (San Francisco and Berkeley) and Lawrence Berkeley National Laboratory institutional review boards for human research, and written informed consent was obtained from all participants according to the Declaration of Helsinki. 


\title{
Image acquisition and pre-processing
}

\section{UCSF}

T1-weighted magnetization prepared rapid gradient echo MRI sequences were acquired for UCSF patients on either a 3 T Siemens Tim Trio $(n=30)$ or a 3 T Siemens Prisma Fit scanner $(n=55)$. Acquisition parameters were similar for both scanners (sagittal slice orientation; slice thickness $=$ $1.0 \mathrm{~mm}$; slices per slab $=160$; in-plane resolution $=1.0 \times 1.0 \mathrm{~mm}$; matrix $=240 \times 256$; repetition time $=2,300 \mathrm{~ms}$; inversion time $=900 \mathrm{~ms}$; flip angle $=9^{\circ}$ ), although echo time slightly differed (Trio: $2.98 \mathrm{~ms}$; Prisma: 2.9ms). Each participant's MRI was segmented and parcellated using Freesurfer 5.3 to define ROIs and extract gray matter volume and cortical thickness measures.

All PET scans were acquired at the Lawrence Berkeley National Laboratory on a Siemens Biograph 6 Truepoint PET/CT scanner. PIB and FTP were synthesized and radiolabeled at the Laboratory's Biomedical Isotope Facility. For FDG-PET scans, participants fasted for at least 6 hours before scanning. A low-dose CT scan was performed for attenuation correction, and PET data were reconstructed using an ordered subset expectation maximization algorithm with weighted attenuation with scatter correction and a $4 \mathrm{~mm}$ Gaussian kernel. PET SUVR images were based on mean uptake over tracer-specific acquisition windows post-injection (30-60 min for FDG, 50-70 $\mathrm{min}$ for PIB, and 80-100 min for FTP) normalized by mean uptake in MRI-defined (Freesurfer- and SUIT-based), tracer-specific reference regions (pons for FDG, cerebellar cortex for PIB, and inferior cerebellar cortex for FTP). Reconstructed image resolution was 6.5 x $6.5 \mathrm{x}$ $7.25 \mathrm{~mm}$. An additional $4 \mathrm{~mm}$ isotropic Gaussian filter was applied to smooth PET images to a final effective $\sim 8 \mathrm{~mm}^{3}$ resolution (matching ADNI scans, see below).

\begin{abstract}
ADNI
MRI and PET acquisition protocols are detailed elsewhere, see www.adni-info.org. For the present study, we used MRI T1-weighted sequences that were segmented and parcellated by Freesurfer 5.3 .

PET scans were acquired according to published protocols and analyzed using tracer-specific acquisition windows: $30-60 \mathrm{~min}$ for $\mathrm{FDG}, 50-70 \mathrm{~min}$ for $\left[{ }^{18} \mathrm{~F}\right]$-Florbetapir (FBP), 90-110 min for $\left[{ }^{18} \mathrm{~F}\right]$-Florbetaben (FBB), and 75-105 min for FTP. Reference regions used mirrored those of UCSF (pons for FDG, cerebellar gray for FBP and FBB, inferior cerebellar gray for FTP). We converted template-based FDG SUVR images from the ADNI database into MRI-based FDG SUVR images with a pons reference region defined via a custom pipeline (Supplementary Methods).
\end{abstract}

All image processing beyond Freesurfer parcellation, including PET pre-processing, warping, and MRI tissue probability segmentation, was performed using Statistical Parametric Mapping (SPM12; Wellcome Trust Center for Neuroimaging, London, UK, http://www.fil.ion.ucl.ac.uk/spm).

\section{Regions and measures of interest}


Desikan atlas-based ROIs were defined on native-space MRIs using Freesurfer 5.3 and applied to all modalities. The isthmus cingulate cortex was used as the RSC ROI and the inferior parietal cortex as IP. The composite MTL region included the hippocampus, amygdala, entorhinal cortex, and parahippocampal cortex. MRI measures of interest include cortical thickness for cortical ROIs and volume divided by total intracranial volume as estimated by FreeSurfer for the MTL ROI. Analyses using amyloid-PET regional values within the ADNI cohort are performed separately for each tracer because the Centiloid transformation has been validated for global, but not regional, amyloid-PET values from different tracers. Our primary analyses are performed within the FBP subsample because it is larger $(n=87)$; results within the FBB subsample $(n=60)$ are reported in Supplementary Fig. 5. For template-space PET analyses, native-space SUVR images were warped to Montreal Neurological Institute (MNI) template-space following deformation parameters defined on respective structural MRIs using SPM12. Centiloids were calculated using equations validated according to established protocols. ${ }^{56}$ Importantly, FDG-PET and MRI measures were reversed so that greater values indicated greater pathology or neurodegeneration for all imaging modalities.

To define regions connected to RSC and IP, we first determined MNI coordinates for RSC and IP, defined as the voxel of greatest auto-correlation with native-space RSC and IP FDG-PET values within an FDG-PET control group using voxelwise regression analyses (Supplementary Methods). We then used these coordinates on neurosynth.org to obtain maps of functional connectivity with RSC or IP. The resulting maps were downloaded from Neurosynth and masked with an in-house GM mask then binarized at the $90^{\text {th }}$ percentile of connectivity to create ROIs of most connected regions, referred to as funcROIs moving forward. The resulting funcROIs are groups of statistically defined voxels and do not necessarily correspond to specific neuroanatomical labels. Finally, the discrete cluster corresponding to auto-correlation with RSC or IP was manually removed (see Supplementary Fig. 1 for the funcROI creation process and Figure $1 \mathrm{~B}$ for an illustration of the final funcROIs). We used mean SUVR values within the funcROI from templatespace amyloid- and FTP-PET images as measures of pathology in connected regions.

\section{Summary mean images}

We created mean summary maps to visualize the patterns of imaging abnormalities in each cohort (Figure 2). FTP- and amyloid-PET abnormalities are shown in mean SUVR units because any elevated cortical signal can be considered pathological. FDG-PET and MRI summary images are shown as statistical maps (deviation from normal controls) because they are more easily interpreted. For these statistical maps, we used W-scores (W, covariate-adjusted z-scores), as described elsewhere. ${ }^{5,57-59}$ FDG-PET W-scores were adjusted for age, and MRI W-scores were adjusted for both age and total intracranial volume (Supplementary Methods). The similarity between imaging abnormality patterns observed in UCSF and ADNI was quantified using a voxelwise spatial correlation approach ${ }^{21,60,61}$; correlations were visualized using a hex scatter plot in MATLAB Version 2015a $\mathrm{a}^{62}$ and performed within a cortical gray matter mask. For these 
medRxiv preprint doi: https://doi.org/10.1101/2021.03.08.21252999; this version posted March 12, 2021. The copyright holder for this preprint (which was not certified by peer review) is the author/funder, who has granted medRxiv a license to display the preprint in perpetuity.

It is made available under a CC-BY-NC-ND 4.0 International license .

analyses, $\mathrm{r}$ values are interpreted qualitatively: given that correlations were based on 252,753 cortical voxels, $p$ values are irrelevant.

\section{Partial volume correction}

To complement our main analyses, we applied a 2-compartment partial volume correction to FDGPET and repeated the analyses. ${ }^{63}$ The applied gray and white matter mask included voxels with a gray matter or white matter probability of $>0.5$ according to SPM12 and excluded voxels that were parcellated as a ventricle by FreeSurfer 5.3.

\section{Statistical analysis}

Demographics across cohorts were compared using a standard t-test or Chi-squared test of association where appropriate. To assess the individual relationships between variables of interest and FDG SUVR in RSC and IP, we used bivariate correlations and partial correlations controlling for disease severity and age. We then used linear regression models to assess the independent contributions of these factors with FDG SUVR in the RSC or IP as the dependent variable, based on prior hypotheses. Regression model fit was evaluated using Bayesian information criteria (BIC). Our disease severity measure is a combination of the CDR sum of boxes (CDR-SB) and MMSE scores. Briefly, each measure is z-scored within cohort then averaged within patient to obtain the disease severity score (Supplementary Fig. 2). We used 2-tailed tests for all analyses and an alpha level of .05 to determine significance. Statistical analyses were performed using Jamovi (version 1.1, www.jamovi.org) and R (version 4.0.2, www.R-project.org).

\section{Data availability statement}

The data that support the findings of this study are available from the corresponding author upon request (memory.ucsf.edu/researchtrials/professional/open-science). Gray matter-masked mean images used in Figure 2 are available on Neurovault (neurovault.org/collections/QNGOIQGC/).

\section{Results}

\section{UCSF participants were significantly younger and more impaired than ADNI participants}

We included two independent cohorts of amyloid-positive participants with Mild Cognitive Impairment or dementia: 85 participants from UCSF and 147 from the ADNI study. A summary of demographic characteristics and comparisons between groups is available in Table 1. Briefly, the UCSF cohort was 10.1 years younger $(t(230)=8.8, p<.001, d=1.20)$ and more clinically impaired on CDR $(t(230)=-5.2, p<.001, d=-0.70$ for CDR-SB) and MMSE $(t(230)=7.4, p<$ $.001, d=1.01)$ scores. To account for these differences, we included age and disease severity as covariates in our analyses. Years of education and the prevalence of the $A P O E \& 4$ allele significantly differed, where ADNI had a higher proportion of $A P O E \varepsilon 4$ carriers ( $68 \%$ versus $54 \%$, $\left.\chi^{2}(1)=4.2, p=.04\right)$ and 0.8 fewer years of education $(p=.02, d=-0.31)$. Sex did not differ between 
medRxiv preprint doi: https://doi.org/10.1101/2021.03.08.21252999; this version posted March 12, 2021. The copyright holder for this preprint (which was not certified by peer review) is the author/funder, who has granted medRxiv a license to display the preprint in perpetuity. It is made available under a CC-BY-NC-ND 4.0 International license .

cohorts $\left(\chi^{2}(1)=0.5, p=.46\right)$. Global amyloid burden as measured by the Centiloid scale ${ }^{56}$ differed such that the UCSF amyloid burden was 12 Centiloids higher $(t(230)=-2.5, p=.01, d=-0.34)$ compared to ADNI.

Demographic comparisons between amyloid-PET tracer subgroups in the ADNI cohort are presented in Supplementary Table 3. The FBB subgroup was slightly younger (74.5 years old versus 76.3 years old in FBP subgroup, $p=.06$ ) and had a higher proportion of $A P O E$ \&4 carriers (80\% versus $60 \%$ in FBP subgroup, $p=.02$ ). Statistical models for ADNI that include amyloidPET measures are performed within the FBP subgroup; all other analyses are performed in the whole group.

\section{Regions of imaging abnormalities were comparable between cohorts though intensity differed}

A visual summary of imaging abnormalities between cohorts is available in Figure 2. Qualitatively, FDG- and FTP-PET abnormalities followed a canonical temporo-parietal-predominant pattern with involvement of dorsolateral prefrontal regions in both cohorts. Cohorts differed primarily on the magnitude of abnormalities, with greater hypometabolism and tau pathology in UCSF. The pattern of gray matter atrophy was temporo-parietal-predominant in the UCSF cohort and MTLpredominant in the ADNI cohort. On amyloid-PET, a diffuse neocortical pattern was noted in both cohorts.

Similarities in imaging patterns across cohorts were also quantified using voxelwise spatial correlations (Figure 2, right panel). Patterns of amyloid-PET and tau-PET were highly similar across cohorts ( $r=.80$ and .81 , respectively). Regarding neurodegeneration biomarkers, patterns of hypometabolism observed in ADNI and UCSF were strongly correlated $(r=.66)$ while patterns of gray matter atrophy showed a weaker spatial similarity $(r=.21)$.

Spatial correlations were also investigated across imaging modalities in each cohort separately (Supplementary Fig. 3). Briefly, average patterns of hypometabolism were more similar to tauPET patterns ( $r=.76$ in UCSF, $r=.55$ in ADNI) than to amyloid-PET ( $r=.28$ in UCSF, $r=.22$ in ADNI) or atrophy ( $r=.58$ in UCSF, $r=.38$ in ADNI) patterns. In both cohorts, the spatial correlation between hypometabolism and tau patterns was the strongest of all pairwise associations and exceeded the similarity between tau and atrophy ( $r=.44$ in UCSF, $r=.38$ in ADNI).

\section{FTP SUVR and local thickness consistently correlate with RSC and IP FDG}

To illustrate individual associations between our hypothesized measures and FDG SUVR in RSC and IP, we used correlation analyses, summarized in Figure 3. Bivariate correlations differed by region and cohort, with FTP SUVR and local thickness displaying the most consistent relationship with regional FDG SUVR across regions and cohorts $(r \mathrm{~s}>.31, p \mathrm{~s}<.01)$. APOE $\varepsilon 4$ was consistently unrelated to regional FDG SUVR (absolute $r \mathrm{~s}<.15, p \mathrm{~s}>.05$ ). 
medRxiv preprint doi: https://doi.org/10.1101/2021.03.08.21252999; this version posted March 12, 2021. The copyright holder for this preprint (which was not certified by peer review) is the author/funder, who has granted medRxiv a license to display the preprint in perpetuity. It is made available under a CC-BY-NC-ND 4.0 International license .

Using partial correlations controlling for age and disease severity, associations with local FTP SUVR and thickness remained significant across regions and cohorts $(r \mathrm{~s}=.24$ to .38 for FTP, $r \mathrm{~s}$ $=.26$ to .59 for thickness; all $p \mathrm{~s}<.01)$. FDG SUVR was often related to FTP SUVR in connected regions (i.e. funcROI FTP), though to a lower magnitude than local measures ( $r \mathrm{~s}=.14$ to $.29, p \mathrm{~s}$ $=<.001$ to .22). Partial correlations between FDG SUVR and FTP SUVR measures were compared using a one-tailed r-to-z transform to statistically assess whether local correlations were stronger than distant correlations given the collinearity between FTP measures. Local FTP-FDG correlations were significantly stronger than funcROI FTP-FDG correlations in the UCSF ( $p=$ .046 for RSC, $p=.001$ for IP) but not $\operatorname{ADNI}(p=.25$ for RSC, $p=.15$ for IP) cohort.

Of note, sample sizes differ for analyses with amyloid-PET in ADNI ( $n=87$ with FBP) and with APOE \&4 ( $n=82$ in UCSF, $n=124$ in ADNI). Amyloid-PET analyses repeated within the FBB subset of ADNI yielded similar results (Supplementary Fig. 5).

\section{Primarily local factors are associated with FDG SUVR in linear regression analyses}

Next, linear regression models were used to test the relative associations of each predictor with FDG SUVR in our cohorts (see Tables 2-3). Multiple regressions were performed separately for each cohort and region where FDG SUVR in RSC or IP is the singular dependent variable. Each hypothesized factor was added individually to assess if it improved the model overall. Local FTP SUVR and thickness were included in all hypothesis-testing models due to their consistently significant bivariate and partial correlations with FDG SUVR shown previously.

The addition of local FTP SUVR and thickness measures (local model) significantly improved models containing only age and disease severity $\left(\Delta R^{2}=.09\right.$ to $.21, \Delta B I C=-9$ to -30$)$, with each local factor contributing significantly and independently ( $p \mathrm{~s}=.08$ to $<.001, \beta=0.16$ to 0.46 ). The addition of MTL volume significantly improved this local model only when predicting RSC FDGSUVR within ADNI ( $p=.008, \Delta R^{2}=.04$ and $\triangle B I C=-3$ compared to local). When using BIC to identify the best model, the local model performed optimally for both RSC and IP in UCSF and IP in ADNI. A model including local factors and pathology in the funcROIs performed well but not optimally within the UCSF cohort, though associations with pathology in connected regions appeared in a negative direction. This flip in sign may have occurred due to collinearity between FTP measures in local and functionally connected regions, as has been described previously. ${ }^{64}$

\section{Complementary analyses on the association between MTL volume and RSC metabolism}

The main discrepancy in the analyses presented above regarded the independent effect of MTL volume on RSC FDG SUVR, which was significant in ADNI $(p=.008)$, but not UCSF $(p=.52)$. We performed exploratory interaction analyses within cohort assessing whether age or disease severity (i.e. the two main factors that differ between the cohorts) were modulating the relationship between MTL volume and RSC FDG SUVR. We did not find an interaction between MTL volume 
medRxiv preprint doi: https://doi.org/10.1101/2021.03.08.21252999; this version posted March 12, 2021. The copyright holder for this preprint (which was not certified by peer review) is the author/funder, who has granted medRxiv a license to display the preprint in perpetuity. It is made available under a CC-BY-NC-ND 4.0 International license .

and age on RSC FDG SUVR ( $p=.50$ in UCSF, $p=.58$ in ADNI). In contrast, a disease severity * MTL volume interaction was found in both cohorts such that the relationship between MTL volume and RSC FDG SUVR was more positive at earlier disease stages (Figure 4; $t=-1.9, p=$ .06 in UCSF; $t=-2.1, p=.046$ in ADNI).

To assess whether the absence of association between MTL volume and RSC FDG SUVR in the UCSF cohort could be driven by the inclusion of non-amnestic phenotypes, we repeated the analyses in the UCSF cohort after excluding patients with the logopenic variant of primary progressive aphasia or posterior cortical atrophy. Results in this subset mirrored those in the whole group, where MTL volume and RSC FDG SUVR were not significantly related in both bivariate correlations $(r=.06, p=.63)$ and linear regression analyses (equivalent to Model 2 in Table 2A, $p=.91$ for MTL).

\section{Results using partial volume-corrected data}

Using FDG partial volume-corrected data, many results remained but were somewhat attenuated. In the partial correlations controlling for age and disease severity, relationships with local thickness remained in the UCSF cohort ( $p=.01$ for RSC, $p=.001$ for IP), but not the ADNI cohort $(p=.20$ for $\mathrm{RSC}, p=.58$ for IP). Relationships with local FTP were attenuated $(p \mathrm{~s}=.04-.36)$. The relationship between RSC FDG SUVR and MTL volume in the ADNI cohort remained $(r=$ $.18, p=.03$; Supplementary Fig. 4).

\section{Discussion}

In two independent cohorts of symptomatic patients on the Alzheimer's continuum, we found that decreased glucose metabolism as measured by FDG-PET associates with local atrophy and tau pathology, with medial temporal atrophy associating at early clinical stages. Molecular pathology in functionally connected regions and the presence of the $A P O E \& 4$ allele did not significantly contribute to hypometabolism after accounting for local factors.

Decreased FDG-PET consistently correlated locally with decreased cortical thickness in the RSC and IP, which is unsurprising given that both are measures of neurodegeneration; this relationship has been reported many times previously. 5,17,18,65 However, FDG-PET and structural MRI-derived measures are not redundant, ${ }^{5,15,16,66,67}$ as is illustrated by the discordant patterns of modality abnormalities in the present cohorts (Figure 2): while patterns of decreased FDG-PET followed a similar temporo-parietal pattern across the two cohorts, decreased gray matter volume was most prominent in the medial (ADNI) or lateral (UCSF) temporal lobes. Given the inconsistencies between cohorts in MRI patterns in contrast with FDG-PET patterns, FDG-PET may be a more reliable measure for detecting an Alzheimer's disease-associated pattern of neurodegeneration. The RSC and IP, while among the most hypometabolic regions, were not always the most atrophic. This discrepancy cannot be explained by one modality simply being more sensitive than the other, though sensitivity to neurodegeneration may differ by region as well as modality. ${ }^{17,18,68}$ In some neurodegenerative diseases, MRI and FDG-PET abnormalities are highly consistent; the 
discrepancy between these modalities appears to be the most salient in Alzheimer's disease. ${ }^{21}$ These findings suggest that measures of glucose metabolism in Alzheimer's disease capture processes beyond local atrophy, as has been postulated previously. ${ }^{18,21}$

Tau-PET correlated locally with decreased FDG-PET independent of co-occurring cortical thinning. This finding agrees with existing literature that links tau aggregation to metabolic dysfunction, as evidenced by the consistent co-localization and correlation between tau-PET and decreased FDG-PET, especially in groups of amyloid-positive individuals like the cohorts presented here. $^{4,18,22,24,26,27}$ Given that FDG-PET primarily captures synaptic activity ${ }^{2}$, tau pathology may disrupt synaptic function ${ }^{69,70}$ and thus reduce regional glucose uptake independently of gross structural change. Additionally, previous work in our lab found that tauPET topography and magnitude are more predictive of longitudinal change in cortical thickness than cross-sectional cortical thickness. ${ }^{60}$ It has been postulated that FDG-PET as a biomarker becomes abnormal earlier than MRI in Alzheimer's disease ${ }^{17,71-74}$ and other neurodegenerative disorders. ${ }^{68,75}$ Taken together, these findings suggest that tau pathology may be more closely linked temporally to metabolic than structural abnormalities. If so, the stronger cross-sectional relationship observed between tau and hypometabolism than between tau and atrophy (Figure 3 and Supplementary Fig. 3) may reflect a tighter temporal link.

We did not find an effect of local amyloid-PET on FDG-PET, which is consistent with other cohorts of amyloid-positive individuals. ${ }^{5,31-35}$ Given that the degree of amyloid pathology reaches a plateau soon after symptom onset ${ }^{76}$ in contrast with the increasing levels of tau pathology, ${ }^{77,78}$ it is likely that any direct influence from amyloid plaque pathology may be difficult to detect given the neurotoxicity of tau pathology at this symptomatic stage.

Lower MTL volume was related to decreased FDG-PET signal in the RSC, but not IP. This regional specificity has been reported previously with hypotheses regarding the underlying mechanisms. ${ }^{28,39}$ For one, the RSC, in contrast to the IP, is proximal to MTL regions, especially the parahippocampal cortex, so this relationship could reflect neurodegeneration of neighboring structures. ${ }^{79}$ The spatial extent of FDG-PET abnormalities is larger than that of structural MRI, ${ }^{22}$ so the observed effect could represent a hypometabolism "halo" surrounding adjacent regions of atrophy. Alternatively, MTL atrophy could result in degeneration of the cingulum bundle, deafferentation of the RSC, and thus decreased postsynaptic activity as measured by FDGPET. ${ }^{18,28,38,39,65,80}$ The MTL is structurally well-connected to the RSC, but not IP, ${ }^{51}$ and hypometabolism has been linked to impaired white matter tract integrity in cognitively impaired patients, ${ }^{35,39,80,81}$ providing evidence for this mechanism.

The relationship between MTL atrophy and RSC FDG-PET was significant only in the ADNI cohort. This cohort specificity could be due to the intrinsic differences in the characteristics of the samples, notably differences in age, disease severity, or inclusion criteria: the ADNI patients were older, less severely impaired, and included patients with more amnestic-predominant presentations than the UCSF participants. Converging evidence suggests that in older patients with pathology- 
proven Alzheimer's disease, MTL atrophy is related to both Alzheimer's disease tau pathology and frequently comorbid TDP-43 pathology, ${ }^{82-84}$ an entity also known as limbic-predominant agerelated TDP-43 encephalopathy ${ }^{85}$ and often associated with hippocampal sclerosis. In the older ADNI cohort, MTL degeneration could therefore stem not only from Alzheimer's disease neuropathology but also from comorbid TDP-43 or hippocampal sclerosis. ${ }^{86}$ However, we did not find evidence that age modulates the relationship between lower MTL volume and RSC hypometabolism (Figure 4), arguing against the hypothesis that older age was the primary driver of the association seen in ADNI. Each cohort was limited in its age range, though, and a broader cohort may be better suited to addressing this question. In addition, the exclusion of non-amnestic clinical phenotypes included in the UCSF cohort did not affect our results and could not explain the distinct patterns observed across cohorts.

In contrast, interaction analyses (Figure 4) showed that the relationship between MTL atrophy and RSC hypometabolism was modulated by disease severity, such that it was more positive at milder levels of impairment. Alzheimer's disease is sometimes referred to as a "disconnection syndrome", where functional and structural connectivity across neural networks are increasingly disrupted over the course of the disease. ${ }^{87,88}$ The relationship between MTL atrophy and RSC hypometabolism could be particularly significant at earlier disease stages because the MTL and RSC become increasingly disconnected over time, affecting disease mechanisms. ${ }^{89}$ This disconnection hypothesis may also explain the lack of an association between regional hypometabolism and molecular pathology in distant but functionally connected regions. Many studies observing this relationship were performed in preclinical populations when network connectivity is relatively robust and may better facilitate disease processes. ${ }^{40}$ Also at early disease stages, molecular pathology burden, especially tau, is spatially restricted, ${ }^{90}$ whereas at later stages it becomes more widespread and more spatially homogeneous, with stronger inter-region correlations within amyloid or tau measures. ${ }^{24}$ Such collinearity affects the statistical power required to detect regionspecific relationships. Nonetheless, these findings conflict with the study by Pascoal et al., ${ }^{34}$ who recently found that amyloid pathology as measured by amyloid-PET in distant regions, but not locally, may induce regional hypometabolism via functional connections, even in patients with Mild Cognitive Impairment. However, this study included phosphorylated tau in the cerebrospinal fluid (CSF p-tau) as a measure of tau pathology, while the present study uses tau-PET. CSF p-tau only moderately correlates with tau-PET, and tau-PET is more closely related to cognitive decline and neurodegeneration than CSF p-tau, so these measures likely capture different processes. ${ }^{91,92}$ It is therefore possible that the reported association between remote amyloid and hypometabolism could still be mediated by tau pathology in humans.

We did not see a relationship between hypometabolism and the presence of the $A P O E$ \&4 allele. This finding is largely consistent with existing literature, where this relationship is more often found in asymptomatic rather than symptomatic individuals. ${ }^{30,31,46}$ Previous studies that have observed this relationship in clinical cohorts did not include tau-PET and either included amyloidnegative individuals or a distinction between $A P O E \& 4$ heterozygotes and homozygotes. ${ }^{47,48}$ 
Additionally, the $A P O E$ \&4-associated decrease in glucose metabolism in Alzheimer's diseaseassociated regions observed in clinically normal cohorts is small compared to metabolic decreases due to clinical neurodegeneration. ${ }^{46}$ Therefore, this small effect may be masked by clinically relevant processes at this stage of the disease.

A strength of the present study is the inclusion of two relatively large complementary samples of biomarker-supported Alzheimer's disease patients. With complementary cohorts, we were able to test our hypothesized factors across a wider range of ages and levels of impairment, allowing for greater generalizability to Alzheimer's disease populations. Our results were consistent across these clinical differences as well as differences in study inclusion criteria, site, and scanner. Additionally, we assessed multiple factors simultaneously to directly compare the relative contributions of each factor and performed analyses both with and without partial volume correction. However, the present study is cross-sectional in design, so findings of distinct relationships at different disease stages should be confirmed in a longitudinal design. Our findings also may not apply to preclinical stages, as our cohorts consisted of only symptomatic Alzheimer's disease patients, or to the more diverse populations that are represented in memory clinics, given the high educational attainment and the high proportion of non-Hispanic White individuals included in the cohorts. Finally, while we assessed multiple factors, there are many other possible determinants of hypometabolism that were not addressed in the current study, including but not limited to white matter degeneration, ${ }^{35}$ local inflammation, ${ }^{93}$ and vascular changes. ${ }^{81}$

In conclusion, we found that posterior cortical hypometabolism in Alzheimer's disease reflects primarily local atrophy and tau pathology of the possible factors tested. Medial temporal atrophy is related to RSC hypometabolism only at early disease stages. Our data also showed that molecular pathology in remote brain regions and the presence of the $A P O E \& 4$ allele may not be related to a greater degree of hypometabolism at the symptomatic stage of Alzheimer's disease. These results suggest that Alzheimer's disease hypometabolism is primarily influenced by neurodegeneration and tau, but not amyloid, pathology, reflecting a tau-centric mechanism of synaptic dysfunction. Given the added value of non-atrophy measures in predicting hypometabolism, FDG-PET and MRI may not be interchangeable measures of Alzheimer's-related neurodegeneration.

\section{Acknowledgments}

We thank patients and families for their commitment.

Avid Radiopharmaceuticals enabled the use of the $\left[{ }^{18} \mathrm{~F}\right] \mathrm{Flortaucipir}$ tracer by providing precursor, but did not provide direct funding and was not involved in data analysis or interpretation.

\section{Funding}

The present study was supported by the National Institutes of Health/National Institute of Aging grants NIH/NIA P50-AG23501 (to GDR, BLM), UCSF ADRC P50-AG023501, P30-AG062422 (to BLM, GDR), P01-AG019724 (to BLM), R01-AG045611 (to GDR), R01-AG034570 (to WJJ), 
medRxiv preprint doi: https://doi.org/10.1101/2021.03.08.21252999; this version posted March 12, 2021. The copyright holder for this preprint (which was not certified by peer review) is the author/funder, who has granted medRxiv a license to display the preprint in perpetuity. It is made available under a CC-BY-NC-ND 4.0 International license .

R01-AG032306 (to HLR), NIH/NINDS R01-NS050915 (to MLG), K99AG065501 (to RLJ), K24AG053435 (to HJR), Rainwater Charitable Foundation (to GDR, WJJ), Alzheimer's Association (to RLJ, AARF:16-443577 and DSM, AACSF:19-617663).

Data collection and sharing for this project were funded by the Alzheimer's Disease Neuroimaging Initiative (ADNI) (National Institutes of Health Grant U01 AG024904) and DOD ADNI (Department of Defense award number W81XWH-12-2-0012). ADNI is funded by the National Institute on Aging, the National Institute of Biomedical Imaging and Bioengineering, and through generous contributions from the following: AbbVie, Alzheimer's Association; Alzheimer's Drug Discovery Foundation; Araclon Biotech; BioClinica, Inc.; Biogen; Bristol-Myers Squibb Company; CereSpir, Inc.; Cogstate; Eisai Inc.; Elan Pharmaceuticals, Inc.; Eli Lilly and Company; EuroImmun; F. Hoffmann-La Roche Ltd and its affiliated company Genentech, Inc.; Fujirebio; GE Healthcare; IXICO Ltd.; Janssen Alzheimer Immunotherapy Research \& Development, LLC.; Johnson \& Johnson Pharmaceutical Research \& Development LLC.; Lumosity; Lundbeck; Merck \& Co., Inc.; Meso Scale Diagnostics, LLC.; NeuroRx Research; Neurotrack Technologies; Novartis Pharmaceuticals Corporation; Pfizer Inc.; Piramal Imaging; Servier; Takeda Pharmaceutical Company; and Transition Therapeutics. The Canadian Institutes of Health Research is providing funds to support ADNI clinical sites in Canada. Private sector contributions are facilitated by the Foundation for the National Institutes of Health (www.fnih.org). The grantee organization is the Northern California Institute for Research and Education, and the study is coordinated by the Alzheimer's Therapeutic Research Institute at the University of Southern California. ADNI data are disseminated by the Laboratory for Neuro Imaging at the University of Southern California.

\section{Competing interests}

Amelia Strom, Leonardo Iaccarino, Lauren Edwards, Orit Lesman-Segev, David SoleimaniMeigooni, Julie Pham, Susan Landau, Howard J. Rosen, Maria Luisa Gorno-Tempini, Renaud La Joie have nothing to disclose. Suzanne L. Baker consults for Genentech. Bruce L Miller receives research support from the NIH/NIA and the Centers for Medicare \& Medicaid Services (CMS) as grants for the Memory and Aging Center. As an additional disclosure, Dr. Miller serves as Medical Director for the John Douglas French Foundation; Scientific Director for the Tau Consortium; Director/Medical Advisory Board of the Larry L. Hillblom Foundation; Scientific Advisory Board Member for the National Institute for Health Research Cambridge Biomedical Research Centre and its subunit, the Biomedical Research Unit in Dementia (UK); and Board Member for the American Brain Foundation (ABF). William J Jagust has served as a consultant to BioClinica, Genentech, and Novartis Pharmaceuticals. Gil D Rabinovici receives research support from Avid Radiopharmaceuticals, GE Healthcare, and Life Molecular Imaging, and has received consulting fees or speaking honoraria from Axon Neurosciences, Avid Radiopharmaceuticals, GE Healthcare, Johnson \& Johnson, Roche, Eisai, Genentech, Merck. He is an associate editor of JAMA Neurology. 
medRxiv preprint doi: https://doi.org/10.1101/2021.03.08.21252999; this version posted March 12, 2021. The copyright holder for this preprint (which was not certified by peer review) is the author/funder, who has granted medRxiv a license to display the preprint in perpetuity.

It is made available under a CC-BY-NC-ND 4.0 International license .

\section{References}

1. Jack CR, Bennett DA, Blennow K, et al. NIA-AA Research Framework: Toward a biological definition of Alzheimer's disease. Alzheimer's Dement. 2018;14(4):535-562. doi:10.1016/j.jalz.2018.02.018

2. Rocher AB, Chapon F, Blaizot X, Baron JC, Chavoix C. Resting-state brain glucose utilization as measured by PET is directly related to regional synaptophysin levels: A study in baboons. Neuroimage. 2003;20:1894-1898. doi:10.1016/j.neuroimage.2003.07.002

3. Nestor PJ, Fryer TD, Smielewski P, Hodges JR. Limbic hypometabolism in Alzheimer's disease and mild cognitive impairment. Ann Neurol. 2003;54:343-351. doi:10.1002/ana.10669

4. Gordon BA, Blazey TM, Christensen J, et al. Tau PET in autosomal dominant Alzheimer's disease: Relationship with cognition, dementia and other biomarkers. Brain. 2019;142:1063-1076. doi:10.1093/brain/awz019

5. La Joie R, Perrotin A, Barre L, et al. Region-Specific Hierarchy between Atrophy, Hypometabolism, and -Amyloid (A ) Load in Alzheimer's Disease Dementia. J Neurosci. 2012;32(46):16265-16273. doi:10.1523/JNEUROSCI.2170-12.2012

6. Sala A, Caprioglio C, Santangelo R, et al. Brain metabolic signatures across the Alzheimer's disease spectrum. Eur J Nucl Med Mol Imaging. 2020;47:256-269. doi:10.1007/s00259-019-04559-2

7. Ferris SH, de Leon MJ, Wolf AP, et al. Positron Emission Tomography in the Study of Aging and Senile Dementia. Neurobiol Aging. 1980;1:127-131.

8. Furst AJ, Rabinovici GD, Rostomian AH, et al. Cognition, glucose metabolism and amyloid burden in Alzheimer's disease. Neurobiol Aging. 2012;33(2):215-225. doi:10.1016/J.NEUROBIOLAGING.2010.03.011

9. Landau SM, Mintun MA, Joshi AD, et al. Amyloid deposition, hypometabolism, and longitudinal cognitive decline. Ann Neurol. 2012;72(4):578-586. doi:10.1002/ana.23650

10. Henkel R, Brendel M, Paolini M, et al. FDG PET Data is Associated with Cognitive Performance in Patients from a Memory Clinic. J Alzheimer's Dis. 2020;78:1-10. doi:10.3233/jad-200826

11. Hedderich DM, Drost R, Goldhardt O, et al. Regional Cerebral Associations Between Psychometric Tests and Imaging Biomarkers in Alzheimer's Disease. Front Psychiatry. 2020;11(August):793. doi:10.3389/fpsyt.2020.00793

12. Catricalà E, Polito $\mathrm{C}$, Presotto $\mathrm{L}$, et al. Neural correlates of naming errors across different neurodegenerative diseases: A FDG-PET study. Neurology. 2020;(Oct). doi:10.1212/wnl.0000000000010967

13. Mosconi L, Berti V, Glodzik L, Pupi A, De Santi S, De Leon MJ. Pre-clinical detection of Alzheimer's disease using FDG-PET, with or without amyloid imaging. J Alzheimer's Dis. 2010;20(3):843-854. doi:10.3233/JAD-2010-091504

14. Krell-Roesch J, Syrjanen JA, Vassilaki M, et al. Brain Regional Glucose Metabolism, 
medRxiv preprint doi: https://doi.org/10.1101/2021.03.08.21252999; this version posted March 12, 2021. The copyright holder for this preprint (which was not certified by peer review) is the author/funder, who has granted medRxiv a license to display the preprint in perpetuity. It is made available under a CC-BY-NC-ND 4.0 International license .

Neuropsychiatric Symptoms, and the Risk of Incident Mild Cognitive Impairment: The Mayo Clinic Study of Aging. Am J Geriatr Psychiatry. Published online 2020. doi:10.1016/j.jagp.2020.06.006

15. Chetelat G, Desgranges B, Landeau B, et al. Direct voxel-based comparison between grey matter hypometabolism and atrophy in Alzheimer, $\mathrm{s}$ disease. Brain. 2008;131:60-71. doi:10.1093/brain/awm288

16. Grothe MJ, Teipel SJ. Spatial patterns of atrophy, hypometabolism, and amyloid deposition in Alzheimer's disease correspond to dissociable functional brain networks. Hum Brain Mapp. 2016;37(1):35-53. doi:10.1002/hbm.23018

17. Kljajevic V, Grothe MJ, Ewers M, Teipel S. Distinct pattern of hypometabolism and atrophy in preclinical and predementia Alzheimer's disease. Neurobiol Aging. 2014;35(9):1973-1981. doi:10.1016/j.neurobiolaging.2014.04.006

18. Sintini I, Schwarz CG, Martin PR, et al. Regional multimodal relationships between tau, hypometabolism, atrophy and fractional anisotropy in atypical Alzheimer's disease. Hum Brain Mapp. 2019;40(5):1618-1631. doi:10.1002/hbm.24473.Regional

19. Yanase D, Matsunari I, Yajima K, et al. Brain FDG PET study of normal aging in Japanese: Effect of atrophy correction. Eur J Nucl Med Mol Imaging. 2005;32(7):794-805. doi:10.1007/s00259-005$1767-2$

20. Samuraki M, Matsunari I, Chen WP, et al. Partial volume effect-corrected FDG PET and grey matter volume loss in patients with mild Alzheimer's disease. Eur J Nucl Med Mol Imaging. 2007;34(10):1658-1669. doi:10.1007/s00259-007-0454-x

21. Bejanin A, Joie R La, Landeau B, et al. Distinct Interplay Between Atrophy and Hypometabolism in Alzheimer's Versus Semantic Dementia. Cereb Cortex. Published online 2018:1-11. doi:10.1093/cercor/bhy069

22. Iaccarino L, Joie R La, Edwards L, et al. Spatial Relationships between Molecular Pathology and Neurodegeneration in the Alzheimer's Disease Continuum. Cereb Cortex. Published online 2020:114. doi:10.1093/cercor/bhaa184

23. Whitwell JL, Graff-Radford J, Tosakulwong N, et al. Imaging correlations of tau, amyloid, metabolism, and atrophy in typical and atypical Alzheimer's disease. Alzheimer's Dement. 2018;14(8):1005-1014. doi:10.1016/j.jalz.2018.02.020

24. Iaccarino L, Tammewar G, Ayakta N, et al. Local and distant relationships between amyloid, tau and neurodegeneration in Alzheimer's Disease. NeuroImage Clin. 2018;17(February):452-464. doi:10.1016/j.nicl.2017.09.016

25. Bischof GN, Jessen F, Fliessbach K, et al. Impact of tau and amyloid burden on glucose metabolism in Alzheimer's disease. Ann Clin Transl Neurol. 2016;3(12):934-939. doi:10.1002/acn3.339

26. Li L, Kang J, Lockhart SN, Adams J, Jagust WJ. Spatially adaptive varying correlation analysis for multimodal neuroimaging data. IEEE Trans Med Imaging. 2019;38(1):113-123. doi:10.1109/TMI.2018.2857221 
medRxiv preprint doi: https://doi.org/10.1101/2021.03.08.21252999; this version posted March 12, 2021. The copyright holder for this preprint (which was not certified by peer review) is the author/funder, who has granted medRxiv a license to display the preprint in perpetuity. It is made available under a CC-BY-NC-ND 4.0 International license .

27. Ossenkoppele R, Schonhaut DR, Schöll M, et al. Tau PET patterns mirror clinical and neuroanatomical variability in Alzheimer's disease. Brain. 2016;139:1551-1567. doi:10.1093/brain/aww027

28. Teipel S, Grothe MJ. Does posterior cingulate hypometabolism result from disconnection or local pathology across preclinical and clinical stages of Alzheimer's disease? Eur J Nucl Med Mol Imaging. 2018;43(3):526-536. doi:10.1007/s00259-015-3222-3.Does

29. Förster S, Grimmer T, Miederer I, et al. Regional Expansion of Hypometabolism in Alzheimer ' $\mathrm{s}$ Disease Follows Amyloid Deposition with Temporal Delay. BPS. 2011;71(9):792-797. doi:10.1016/j.biopsych.2011.04.023

30. Carbonell F, Zijdenbos AP, Bedell BJ. Spatially Distributed Amyloid- $\beta$ Reduces Glucose Metabolism in Mild Cognitive Impairment. $J$ Alzheimers Dis. 2020;73(2):543-557. doi:10.3233/JAD-190560

31. Rabinovici GD, Furst AJ, Alkalay A, et al. Increased metabolic vulnerability in early-onset Alzheimer's disease is not related to amyloid burden. Brain. 2010;133(2):512-528. doi:10.1093/brain/awp326

32. Lehmann M, Ghosh PM, Madison C, et al. Diverging patterns of amyloid deposition and hypometabolism in clinical variants of probable Alzheimer's disease. Brain. 2013;136(3):844-858. doi:10.1093/brain/aws327

33. Altmann A, Ng B, Landau SM, Jagust WJ, Greicius MD. Regional brain hypometabolism is unrelated to regional amyloid plaque burden. Brain. 2015;138(12):3734-3746. doi:10.1093/brain/awv278

34. Pascoal TA, Mathotaarachchi S, Kang MS, et al. A $\beta$-induced vulnerability propagates via the brain's default mode network. Nat Commun. 2019;10(2353):1-39. doi:10.1038/s41467-019-10217-w

35. Schilling LP, Pascoal TA, Zimmer ER, et al. Regional Amyloid- $\beta$ Load and White Matter Abnormalities Contribute to Hypometabolism in Alzheimer's Dementia. Mol Neurobiol. 2019;56:4916-4924. doi:10.1007/s12035-018-1405-1

36. Baron JC, Bousser MG, Comar D, Castaigne P. "Crossed cerebellar diaschisis" in human supratentorial brain infarction. Trans Am Neurol Assoc. 1981;105:459-461.

37. Gold L, Lauritzen M. Neuronal deactivation explains decreased cerebellar blood flow in response to focal cerebral ischemia or suppressed neocortical function. Proc Natl Acad Sci U S A. 2002;99(11):7699-7704. doi:10.1073/pnas.112012499

38. Meguro K, Blaizot X, Kondoh Y, Le Mestric C, Baron JC, Chavoix C. Neocortical and hippocampal glucose hypometabolism following neurotoxic lesions of the entorhinal and perirhinal cortices in the non-human primate as shown by PET. Implications for Alzheimer's disease. Brain. 1999;122(8):1519-1531. doi:10.1093/brain/122.8.1519

39. Villain N, Viader F, Sayette V De, et al. Relationships between Hippocampal Atrophy, White Matter Disruption, and Gray Matter Hypometabolism in Alzheimer' s Disease. $J$ Neurosci. 2008;28(24):6174-6181. doi:10.1523/JNEUROSCI.1392-08.2008 
medRxiv preprint doi: https://doi.org/10.1101/2021.03.08.21252999; this version posted March 12, 2021. The copyright holder for this preprint (which was not certified by peer review) is the author/funder, who has granted medRxiv a license to display the preprint in perpetuity. It is made available under a CC-BY-NC-ND 4.0 International license .

40. Adams JN, Jagust J, Lockhart SN, Li L, Berkeley L. Relationships Between Tau and Glucose Metabolism Reflect Alzheimer's Disease Pathology in Cognitively Normal Older Adults. Cereb Cortex. Published online 2018:1-13. doi:10.1093/cercor/bhy078

41. Hanseeuw BJ, Betensky RA, Jacobs HIL, et al. Association of Amyloid and Tau With Cognition in Preclinical Alzheimer Disease. JAMA Neurol. 2019;02114. doi:10.1001/jamaneurol.2019.1424

42. Protas HD, Chen K, Langbaum JBS, et al. Posterior Cingulate Glucose Metabolism, Hippocampal Glucose Metabolism, and Hippocampal Volume in Cognitively Normal, Late-Middle-Aged Persons at 3 Levels of Genetic Risk for Alzheimer Disease. JAMA Neurol. 2013;70(3):320-325. doi:10.1001/2013.jamaneurol.286.Posterior

43. Perkins M, Wolf AB, Chavira B, et al. Altered Energy Metabolism Pathways in the Posterior Cingulate in Young Adult Apolipoprotein E 4 Carriers. J Alzheimer's Dis. 2016;53:95-106. doi:10.3233/JAD-151205

44. Valla J, Yaari R, Wolf AB, et al. Reduced Posterior Cingulate Mitochondrial Activity in Expired Young Adult Carriers of the APOE 4 Allele, the Major Late-Onset Alzheimer's Susceptibility Gene. J Alzheimer's Dis. 2011;22(1):307-313. doi:10.3233/JAD-2010-100129.Reduced

45. Jagust WJ, Landau SM. Apolipoprotein E, not fibrillar $\beta$-amyloid, reduces cerebral glucose metabolism in normal aging. $J$ Neurosci. 2012;32(50):18227-18233. doi:10.1523/JNEUROSCI.3266-12.2012

46. Knopman DS, Jack CR, Wiste HJ, et al. 18F-fluorodeoxyglucose positron emission tomography, aging, and apolipoprotein E genotype in cognitively normal persons. Neurobiol Aging. 2014;35:2096-2106. doi:10.1016/j.neurobiolaging.2014.03.006

47. Ossenkoppele R, van der Flier WM, Zwan MD, et al. Differential effect of APOE genotype on amyloid load and glucose metabolism in AD dementia. Neurology. 2013;80:359-365. doi:10.1212/WNL.0b013e31827f0889 This

48. Drzezga A, Riemenschneider M, Strassner B, et al. Cerebral glucose metabolism in patients with $\mathrm{AD}$ and different APOE genotypes. Neurology. 2005;64(January):102-107. doi:10.1212/01.WNL.0000148478.39691.D3

49. Corder EH, Jelic V, Basun H, et al. No Difference in Cerebral Glucose Metabolism in Patients With Alzheimer Disease and Differing Apolipoprotein E Genotypes. Arch Neurol. 1997;54:273-277.

50. Minoshima S, Giordani B, Berent S, Frey KA, Foster NL, Kuhl DE. Metabolic reduction in the posterior cingulate cortex in very early Alzheimer's disease. Ann Neurol. 1997;42(1):85-94. doi:10.1002/ana.410420114

51. Bubb EJ, Metzler-Baddeley C, Aggleton JP. The cingulum bundle: Anatomy, function, and dysfunction. Neurosci Biobehav Rev. 2018;92(May):104-127. doi:10.1016/j.neubiorev.2018.05.008

52. Albert MS, DeKosky ST, Dickson D, et al. The Diagnosis of Mild Cognitive Impairment due to Alzheimer's Disease: Recommendations from the National Institute on Aging-Alzheimer's Association Workgroups on Diagnostic Guidelines for Alzheimer's Disease. Alzheimer's Dement. 2011;7(3):270-279. doi:10.1016/j.jalz.2011.03.008 
medRxiv preprint doi: https://doi.org/10.1101/2021.03.08.21252999; this version posted March 12, 2021. The copyright holder for this preprint (which was not certified by peer review) is the author/funder, who has granted medRxiv a license to display the preprint in perpetuity.

It is made available under a CC-BY-NC-ND 4.0 International license .

53. McKhann GM, Knopman DS, Chertkow H, et al. The diagnosis of dementia due to Alzheimer's disease: Recommendations from the National Institute on Aging-Alzheimer's Association workgroups on diagnostic guidelines for Alzheimer's disease. Alzheimer's Dement. 2011;7(3):263269. doi:10.1016/j.jalz.2011.03.005

54. Reams N, Eckner JT, Almeida AA, et al. A clinical approach to the diagnosis of traumatic encephalopathy syndrome: A review. JAMA Neurol. 2016;73(6):743-749. doi:10.1001/jamaneurol.2015.5015

55. Villeneuve S, Rabinovici GD, Cohn-Sheehy BI, et al. Existing Pittsburgh Compound-B positron emission tomography thresholds are too high: Statistical and pathological evaluation. Brain. 2015;138(7):2020-2033. doi:10.1093/brain/awv112

56. Klunk WE, Koeppe RA, Price JC, et al. The Centiloid project: Standardizing quantitative amyloid plaque estimation by PET. Alzheimer's Dement. 2015;11:1-15. doi:10.1016/j.jalz.2014.07.003

57. van Loenhoud AC, Wink AM, Groot C, et al. A neuroimaging approach to capture cognitive reserve: Application to Alzheimer's disease. Hum Brain Mapp. 2017;38:4703-4715. doi:10.1002/hbm.23695

58. Jack CR, Petersen RC, Xu YC, et al. Medial temporal atrophy on MRI in normal aging and very mild Alzheimer's disease. Neurology. 1997;49:786-794. doi:10.1212/WNL.49.3.786

59. Ossenkoppele R, Cohn-sheehy BI, Joie R La, et al. Atrophy Patterns in Early Clinical Stages Across Distinct Phenotypes of Alzheimer 's Disease. Hum Brain Mapp. 2015;36:4421-4437. doi:10.1002/hbm.22927

60. La Joie R, Visani A V., Baker SL, et al. Prospective longitudinal atrophy in Alzheimer's disease correlates with the intensity and topography of baseline tau-PET. Sci Transl Med. 2020;12(524). doi:10.1126/scitranslmed.aau5732

61. Ossenkoppele R, Iaccarino L, Schonhaut DR, et al. Tau covariance patterns in Alzheimer's disease patients match intrinsic connectivity networks in the healthy brain. NeuroImage Clin. 2019;23. doi:10.1016/j.nicl.2019.101848

62. Gordon. hexscatter.m. Published online 2020. https://www.mathworks.com/matlabcentral/fileexchange/45639-hexscatter-m

63. Meltzer CC, Leal JP, Mayberg HS, Wagner HN, Frost JJ. Correction of PET Data for Partial Volume Effects in Human Cerebral Cortex by MR Imaging. J Comput Assist Tomogr. 1990;14(4):561-570.

64. Tomaschek F, Hendrix P, Baayen RH. Strategies for addressing collinearity in multivariate linguistic data. J Phon. 2018;71:249-267. doi:10.1016/j.wocn.2018.09.004

65. Chetelat G, Villain N, Desgranges B, Eustache F, Baron J. Posterior cingulate hypometabolism in early Alzheimer's disease: what is the contribution of local atrophy versus disconnection? Brain. 2009;132(12):1-2. doi:10.1093/brain/awp253

66. Matsuda H, Kitayama N, Ohnishi T, et al. Longitudinal evaluation of both morphologic and functional changes in the same individuals with Alzheimer's disease. $J$ Nucl Med. 2002;43(3):304311. 
medRxiv preprint doi: https://doi.org/10.1101/2021.03.08.21252999; this version posted March 12, 2021. The copyright holder for this preprint (which was not certified by peer review) is the author/funder, who has granted medRxiv a license to display the preprint in perpetuity.

It is made available under a CC-BY-NC-ND 4.0 International license .

67. Benvenutto A, Giusiano B, Koric L, et al. Imaging Biomarkers of Neurodegeneration in Alzheimer's Disease: Distinct Contributions of Cortical MRI Atrophy and FDG-PET Hypometabolism. $J$ Alzheimer's Dis. 2018;65(4):1147-1157. doi:10.3233/JAD-180292

68. Albrecht F, Ballarini T, Neumann J, Schroeter ML. FDG-PET hypometabolism is more sensitive than MRI atrophy in Parkinson's disease: A whole-brain multimodal imaging meta-analysis. NeuroImage Clin. 2019;21. doi:10.1016/j.nicl.2018.11.004

69. Jadhav S, Katina S, Kovac A, Kazmerova Z, Novak M, Zilka N. Truncated tau deregulates synaptic markers in rat model for human tauopathy. Front Cell Neurosci. 2015;9(FEB):1-14. doi:10.3389/fncel.2015.00024

70. Callahan LM, Vaules WA, Coleman PD. Quantitative Decrease in Synaptophysin Message Expression and Increase in Cathepsin D Message Expression in Alzheimer Disease Neurons Containing Neurofibrillary Tangles. $J$ Neuropathol Exp Neurol. 1999;58(3):275-287. http://ibrary1.nida.ac.th/termpaper6/sd/2554/19755.pdf

71. Jack CR, Knopman DS, Jagust WJ, et al. Hypothetical model of dynamic biomarkers of the Alzheimer's pathological cascade. Lancet Neurol. 2010;9(1):119-128. doi:10.1016/S14744422(09)70299-6

72. Shaffer JL, Petrella JR, Sheldon FC, et al. Predicting Cognitive Decline in Subjects at Risk for Alzheimer Disease by Using Combined Cerebrospinal Fluid, MR Imaging, and PET Biomarker. Radiology. 2013;266(2):583-591. doi:10.1148/radiol.12120010/-/DC1

73. Morinaga A, Ono K, Ikeda T, et al. A comparison of the diagnostic sensitivity of MRI, CBF-SPECT, FDG-PET and cerebrospinal fluid biomarkers for detecting Alzheimer's disease in a memory clinic. Dement Geriatr Cogn Disord. 2010;30:285-292. doi:10.1159/000320265

74. Ferrari BL, De Carvalho Campos Neto G, Nucci MP, et al. The accuracy of hippocampal volumetry and glucose metabolism for the diagnosis of patients with suspected Alzheimer's disease, using automatic quantitative clinical tools. Med (United States). 2019;98(45). doi:10.1097/MD.0000000000017824

75. Kwon KY, Choi CG, Kim JS, Lee MC, Chung SJ. Comparison of Brain MRI and 18F-FDG PET in the Differential Diagnosis of Multiple System Atrophy from Parkinson's Disease. Mov Disord. 2007;22(16):2352-2358. doi:10.1002/mds.21714

76. Jack CR, Wiste HJ, Lesnick TG, et al. Brain $\beta$-amyloid load approaches a plateau. Neurology. 2013;80(10):890-896. doi:10.1212/WNL.0b013e3182840bbe

77. Harrison TM, La Joie R, Maass A, et al. Longitudinal Tau Accumulation and Atrophy in Aging and Alzheimer Disease. Ann Neurol. 2019;85:229-240. doi:10.1002/ana.25406

78. Jack CR, Wiste HJ, Weigand SD, et al. Predicting future rates of tau accumulation on PET. Brain. 2020;143:3136-3150. doi:10.1093/brain/awaa248

79. Zhou J, Gennatas ED, Kramer JH, Miller BL, Seeley WW. Predicting Regional Neurodegeneration from the Healthy Brain Functional Connectome. Neuron. 2012;73(6):1216-1227. doi:10.1016/j.neuron.2012.03.004 
medRxiv preprint doi: https://doi.org/10.1101/2021.03.08.21252999; this version posted March 12, 2021. The copyright holder for this preprint (which was not certified by peer review) is the author/funder, who has granted medRxiv a license to display the preprint in perpetuity.

It is made available under a CC-BY-NC-ND 4.0 International license .

80. $\mathrm{Li} \mathrm{J}, \mathrm{Hu} \mathrm{W}$. Glucose metabolism measured by positron emission tomography is reduced in patients with white matter presumably ischemic lesions. Med Sci Monit. 2014;20:1525-1530. doi:10.12659/MSM.892137

81. Verger A, Hossu G, Kearney-Schwartz A, et al. Grey-Matter Metabolism in Relation with WhiteMatter Lesions in Older Hypertensive Patients with Subjective Memory Complaints: A Pilot VoxelBased Analysis Study. Cerebrovasc Dis. 2016;42:106-109. doi:10.1159/000445527

82. de Flores R, Wisse LEM, Das SR, et al. Contribution of mixed pathology to medial temporal lobe atrophy in Alzheimer's disease. Alzheimer's Dement. 2020;(January):3-5. doi:10.1002/alz.12079

83. Josephs KA, Whitwell JL, Knopman DS, et al. Abnormal TDP-43 immunoreactivity in AD modifies clinicopathologic and radiologic phenotype. Neurology. 2008;70:1850-1857. doi:10.1212/01.wnl.0000304041.09418.b1

84. Yu L, Boyle PA, Dawe RJ, Bennett DA, Arfanakis K. Contribution of TDP and hippocampal sclerosis to hippocampal volume loss in older-old persons. Neurology. 2020;94:1-11. doi:10.1212/WNL.0000000000008679

85. Nelson PT, Dickson DW, Trojanowski JQ, et al. Limbic-predominant age-related TDP-43 encephalopathy (LATE): consensus working group report. Brain. Published online 2019. doi:10.1093/brain/awz099

86. Botha H, Mantyh WG, Murray ME, et al. FDG-PET in tau-negative amnestic dementia resembles that of autopsy-proven hippocampal sclerosis. Brain. 2018;141:1201-1217. doi:10.1093/brain/awy049

87. Smailovic U, Koenig T, Savitcheva I, et al. Regional disconnection in Alzheimer dementia and amyloid positive MCI: Association of EEG functional connectivity and brain glucose metabolism. Brain Connect. Published online 2020:1-31. doi:10.1089/brain.2020.0785

88. Scherr M, Utz L, Tahmasian M, et al. Effective connectivity in the default mode network is distinctively disrupted in Alzheimer's disease-A simultaneous resting-state FDG-PET/fMRI study. Hum Brain Mapp. Published online 2019:1-10. doi:10.1002/hbm.24517

89. Jacobs HIL, Hedden T, Schultz AP, et al. Structural tract alterations predict downstream tau accumulation in amyloid-positive older individuals. Nat Neurosci. 2018;21(March):424-431. doi:10.1038/s41593-018-0070-z

90. Lockhart SN, Schöll M, Baker SL, et al. Amyloid and tau PET demonstrate region-specific associations in normal older people. Neuroimage. 2017;150(August 2016):191-199. doi:10.1016/j.neuroimage.2017.02.051

91. Mattsson N, Schöll M, Strandberg O, et al. 18 F-AV-1451 and CSF T-tau and P-tau as biomarkers in Alzheimer's disease . EMBO Mol Med. 2017;9(9):1212-1223. doi:10.15252/emmm.201707809

92. La Joie R, Bejanin A, Fagan AM, et al. Associations between [18F]AV1451 tau PET and CSF measures of tau pathology in a clinical sample. Neurology. 2018;90(4):E282-E290. doi:10.1212/WNL.0000000000004860 
medRxiv preprint doi: https://doi.org/10.1101/2021.03.08.21252999; this version posted March 12, 2021. The copyright holder for this preprint (which was not certified by peer review) is the author/funder, who has granted medRxiv a license to display the preprint in perpetuity. It is made available under a CC-BY-NC-ND 4.0 International license.

93. Tondo G, Iaccarino L, Caminiti SP, et al. The combined effects of microglia activation and brain glucose hypometabolism in early-onset Alzheimer's disease. Alzheimer's Res Ther. 2020;12(1):110. doi:10.1186/s13195-020-00619-0 

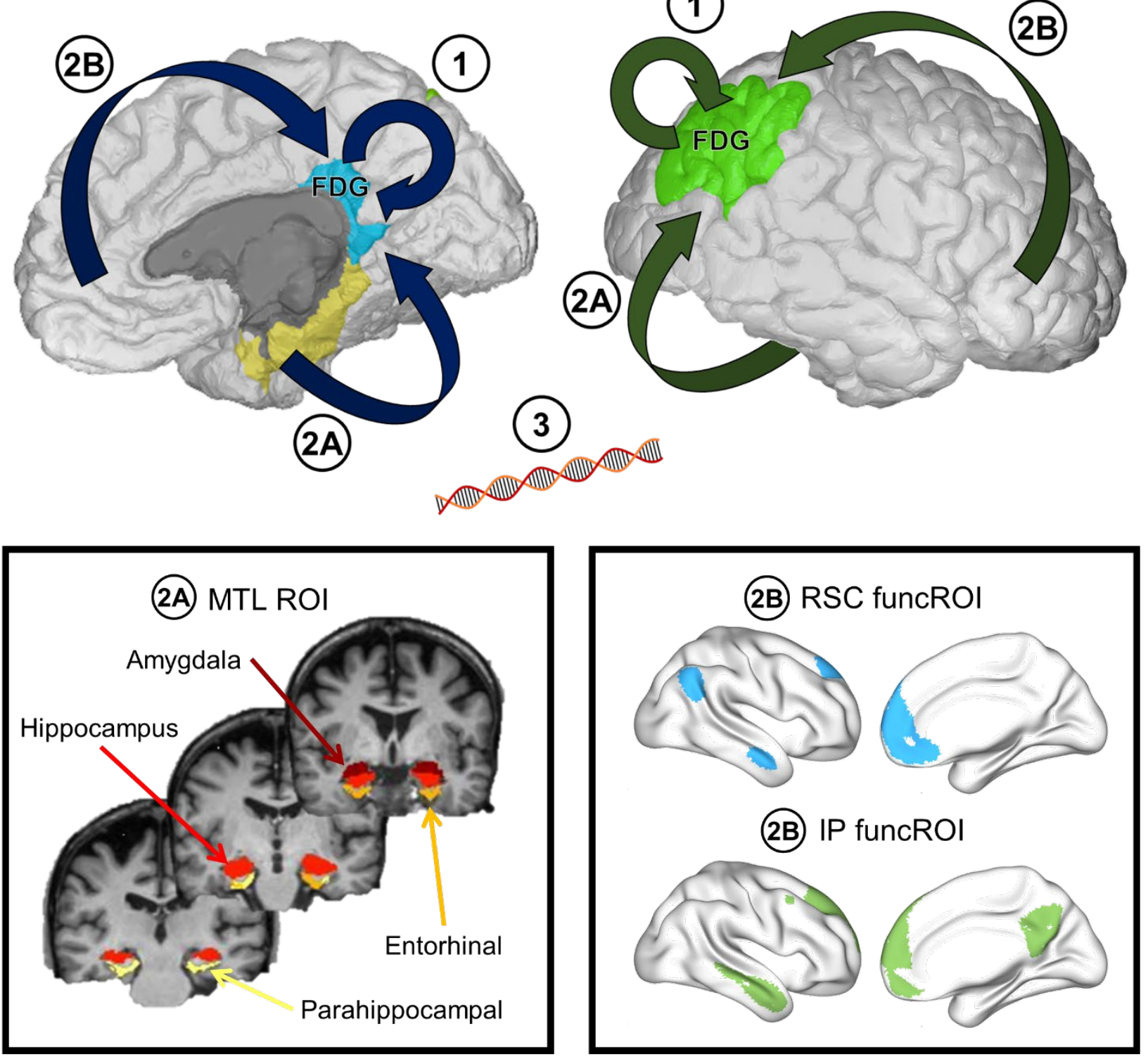

Figure 1. Schematic of potential hypometabolism-related mechanisms and regions of interest used. Hypometabolism in the primary regions of interest (blue $=$ retrosplenial cortex, green $=$ inferior parietal lobe) may result from local molecular pathology and atrophy (1), from distant effects of medial temporal atrophy (2A) or molecular pathology in functionally connected regions (2B), and/or from the presence of the $A P O E \varepsilon 4$ allele (3). Yellow on top panel = medial temporal lobe. The medial temporal lobe ROI consists of the amygdala, hippocampus, entorhinal cortex, and parahippocampal cortex (bottom left panel). The funcROIs were derived from resting-state functional data from healthy controls for each primary region of interest separately (bottom right panel). 
medRxiv preprint doi: https://doi.org/10.1101/2021.03.08.21252999; this version posted March 12, 2021. The copyright holder for this preprint (which was not certified by peer review) is the author/funder, who has granted medRxiv a license to display the preprint in perpetuity.

It is made available under a CC-BY-NC-ND 4.0 International license.

\begin{tabular}{l|c|c|c|c} 
& UCSF & ADNI & \multicolumn{2}{|c}{ Comparison } \\
\cline { 4 - 5 } & $(\mathbf{n = 8 5})$ & $(\mathbf{n = 1 4 7 )}$ & Effect size & $\mathrm{p}$ \\
\hline Age & $65.2(9.6)$ & $75.3(7.8)$ & $\mathrm{d}=1.2$ & $<.001$ \\
\hline Sex (\% F) & $51 \%$ & $46 \%$ & $\mathrm{~V}=0.05$ & .46 \\
\hline Education & $16.7(2.3)$ & $15.9(2.6)$ & $\mathrm{d}=-0.31$ & .02 \\
\hline CDR-Global (\% $\geq 1)$ & $47 \%$ & $21 \%$ & $\mathrm{~V}=0.27$ & $<.001$ \\
\hline CDR-SB & $4.26(2.2)$ & $2.74(2.1)$ & $\mathrm{d}=-0.70$ & $<.001$ \\
\hline MMSE & $21.2(6.2)$ & $25.8(3.4)$ & $\mathrm{d}=1.01$ & $<.001$ \\
\hline APOE \&4 carrier (\%, missing N) & $53 \%, 9$ & $68 \%, 23$ & $\mathrm{~V}=0.15$ & .03 \\
\hline Amyloid-PET burden (Centiloids) & $98(30)$ & $86(39)$ & $\mathrm{d}=-0.34$ & .01 \\
\hline Amyloid tracer (FBP/FBB/PIB) & $0 / 0 / 85$ & $87 / 60 / 0$ & - & -
\end{tabular}

Table 1. Demographic summary and cohort comparison.

Continuous variables are shown as mean (standard deviation). For comparisons between cohorts, $\chi^{2}$ tests of association were used for discrete variables (Cramer's V as effect size), MannWhitney tests were used for ordinal variables (Cohen's $d$ as effect size) and t-tests were used for continuous variables (Cohen's d as effect size). $\mathrm{CDR}=$ Clinical Dementia Rating, $\mathrm{CDR}-\mathrm{SB}=$ Sum of Boxes score, MMSE $=$ Mini Mental State Exam, FBP $={ }^{18}$ F-Florbetapir, FBB $=$ ${ }^{18} \mathrm{~F}=$ Florbetaben, $\mathrm{PIB}={ }^{11} \mathrm{C}$-Pittsburgh compound-B. 


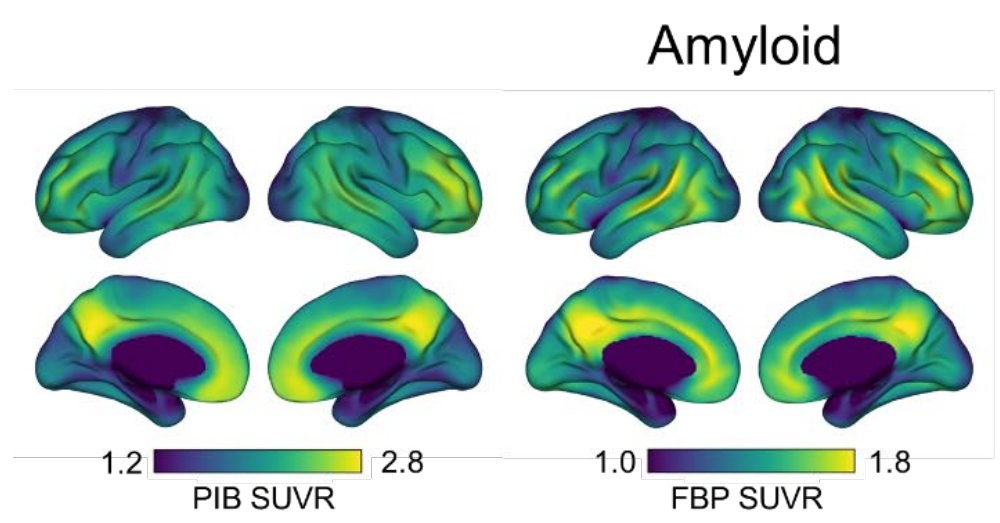

Tau

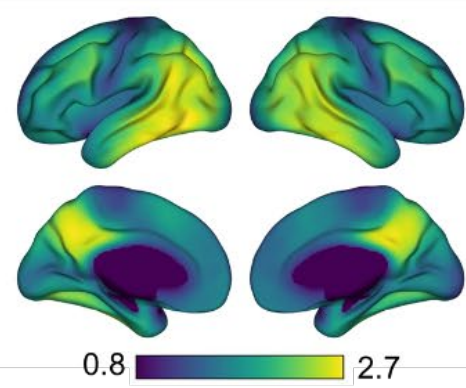

FTP SUVR

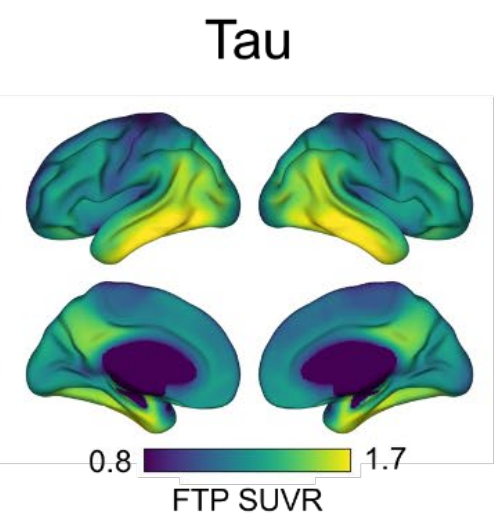

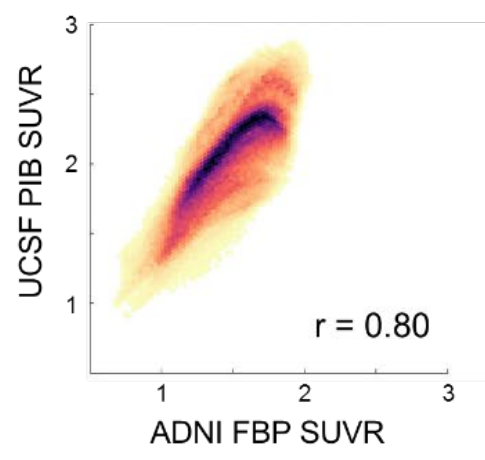

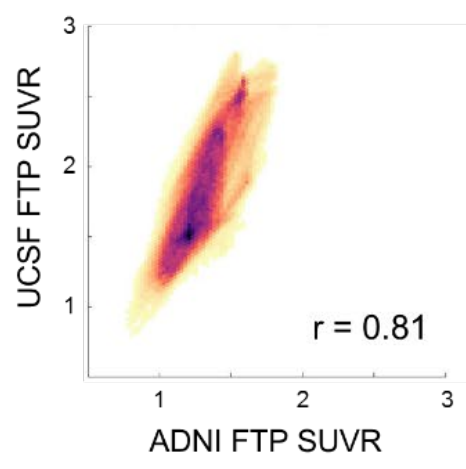

\section{Hypometabolism}
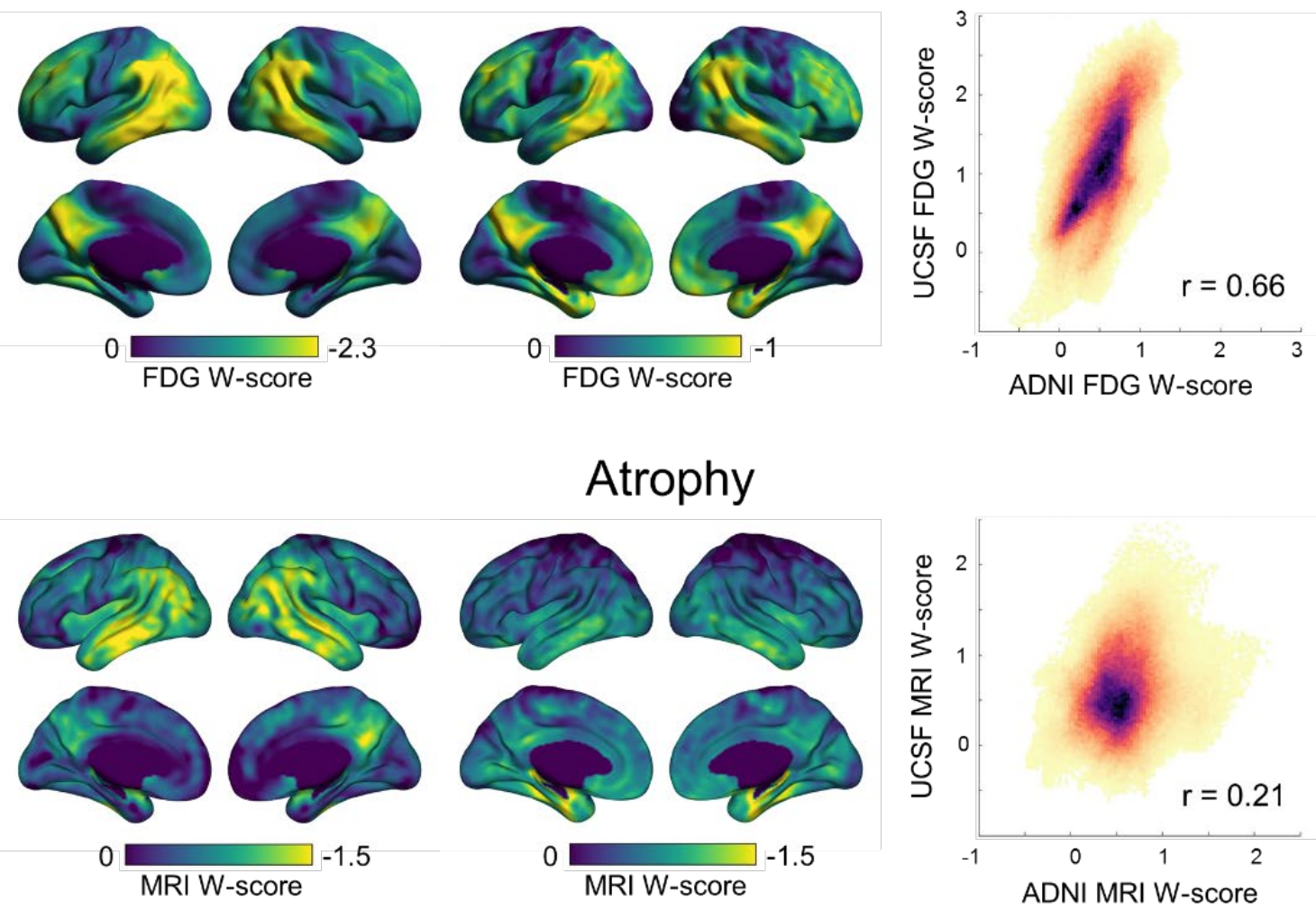

UCSF
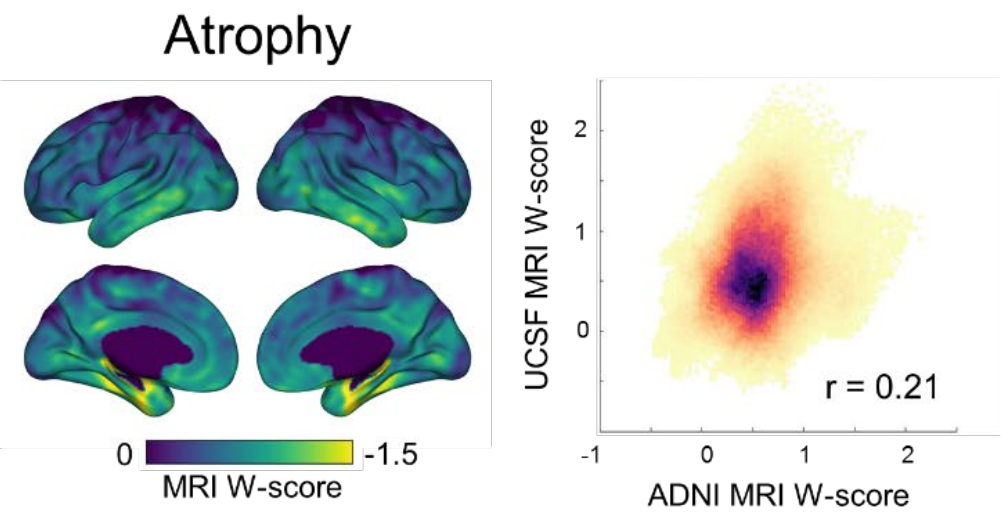

\section{ADNI}


medRxiv preprint doi: https://doi.org/10.1101/2021.03.08.21252999; this version posted March 12, 2021. The copyright holder for this preprint (which was not certified by peer review) is the author/funder, who has granted medRxiv a license to display the preprint in perpetuity. It is made available under a CC-BY-NC-ND 4.0 International license.

Figure 2. Summaries of imaging modalities, presented as voxelwise means within each cohort. Amyloid- and FTP-PET are presented in SUVR units and FDG-PET and MRI volume in age-adjusted z-score, or W-score, units compared to cognitively normal controls. The scales were adapted for each cohort and modality. Scatter plots (right panel) display a voxel-by-voxel correlation between cohort mean images, with ADNI mean modality values represented on the $\mathrm{x}$ axis and UCSF on the y-axis. All voxels from a cortical gray matter mask are included. Color represents the density of represented voxels. Higher $r$ values indicate greater spatial similarity between mean cohort images. 

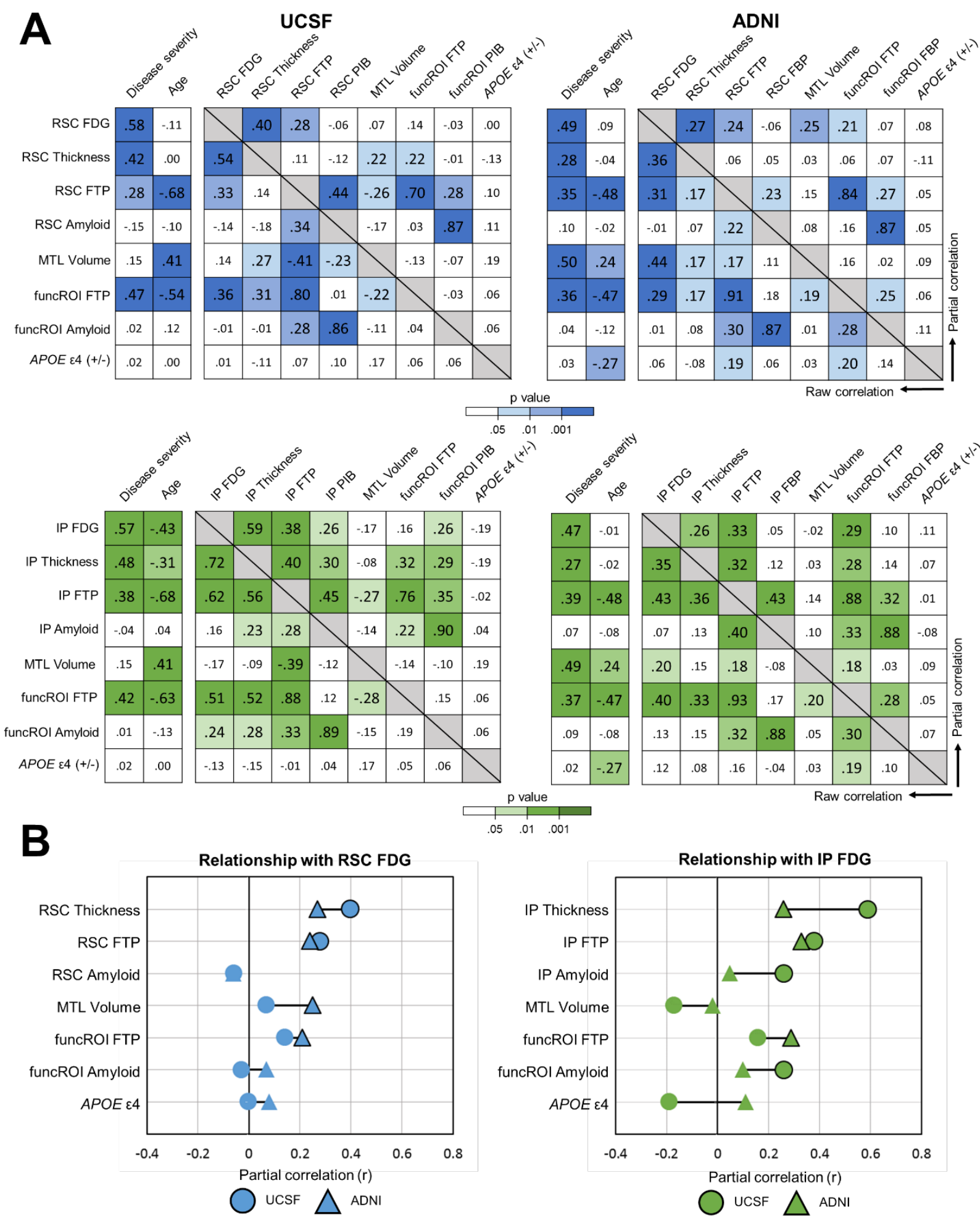

$\begin{array}{llll}05 & .01 & .001\end{array}$

Figure 3. Correlations across measures of interest. (A) Correlation matrices with bivariate correlations in the bottom left portion and partial correlations controlling for age and disease severity in the top right. Color saturation corresponds to p-value. (B) An alternative presentation of partial correlations with FDG in RSC or IP with a direct visual comparison between ADNI 
medRxiv preprint doi: https://doi.org/10.1101/2021.03.08.21252999; this version posted March 12, 2021. The copyright holder for this preprint (which was not certified by peer review) is the author/funder, who has granted medRxiv a license to display the preprint in perpetuity. It is made available under a CC-BY-NC-ND 4.0 International license.

(triangles) and UCSF (circle) cohorts. The presence of shape border reflects statistical significance defined as $\mathrm{p}<.05$. MTL volume was divided by total intracranial volume before analyses. 
medRxiv preprint doi: https://doi.org/10.1101/2021.03.08.21252999; this version posted March 12, 2021. The copyright holder for this preprint (which was not certified by peer review) is the author/funder, who has granted medRxiv a license to display the preprint in perpetuity.

It is made available under a CC-BY-NC-ND 4.0 International license .

\begin{tabular}{|c|c|c|c|c|c|c|c|c|c|c|}
\hline \multirow{2}{*}{$\begin{array}{l}\text { A. RSC FDG } \\
\text { Predictors }\end{array}$} & \multicolumn{2}{|c|}{ Model 0} & \multicolumn{2}{|c|}{ Model 1} & \multicolumn{2}{|c|}{ Model 2} & \multicolumn{2}{|c|}{ Model 3} & \multicolumn{2}{|c|}{ Model 4} \\
\hline & $\beta$ & $\mathrm{p}$ & $\beta$ & $\mathrm{p}$ & $\beta$ & $\mathrm{p}$ & $\beta$ & $\mathrm{p}$ & $\beta$ & $\mathrm{p}$ \\
\hline Disease severity & 0.60 & $<.001$ & 0.38 & $<.001$ & 0.36 & $<.001$ & 0.44 & $<.001$ & 0.37 & $<.001$ \\
\hline Age & 0.01 & .88 & 0.15 & .15 & 0.14 & .24 & 0.17 & .13 & 0.20 & .10 \\
\hline RSC thickness & - & - & 0.34 & $<.001$ & 0.32 & $<.001$ & 0.37 & $<.001$ & 0.32 & .001 \\
\hline RSC FTP & - & - & 0.28 & .02 & 0.30 & .01 & 0.59 & .001 & 0.34 & .007 \\
\hline MTL volume & - & - & - & - & 0.06 & .52 & - & - & - & - \\
\hline funcROI FTP & - & - & - & - & - & - & -0.34 & .03 & - & - \\
\hline funcROI PIB & - & - & - & - & - & - & -0.15 & .10 & - & - \\
\hline APOE $\varepsilon 4$ & - & - & - & - & - & - & - & - & 0.02 & .90 \\
\hline $\mathbf{R}^{2}\left(\Delta \mathbf{R}^{2}\right)$ & \multicolumn{2}{|c|}{0.33 (Ref) } & \multicolumn{2}{|c|}{$0.47(0.15)$} & \multicolumn{2}{|c|}{$0.47(0.15)$} & \multicolumn{2}{|c|}{$0.51(0.18)$} & \multicolumn{2}{|c|}{$0.51(0.15)$} \\
\hline $\operatorname{BIC}\left(\Delta \mathrm{BIC}_{0}\right)$ & \multicolumn{2}{|c|}{-103 (Ref) } & \multicolumn{2}{|c|}{$-114(-11)$} & \multicolumn{2}{|c|}{$-110(-7)$} & \multicolumn{2}{|c|}{$-111(-8)$} & \multicolumn{2}{|c|}{$-110(-7)$} \\
\hline
\end{tabular}

\begin{tabular}{|c|c|c|c|c|c|c|c|c|c|c|}
\hline \multirow{2}{*}{$\begin{array}{l}\text { B. IP FDG } \\
\text { Predictors }\end{array}$} & \multicolumn{2}{|c|}{ Model 0} & \multicolumn{2}{|c|}{ Model 1} & \multicolumn{2}{|c|}{ Model 2} & \multicolumn{2}{|c|}{ Model 3} & \multicolumn{2}{|c|}{ Model 4} \\
\hline & $\beta$ & $p$ & $\beta$ & $\mathrm{p}$ & $\beta$ & $\mathrm{p}$ & $\beta$ & $\mathrm{p}$ & $\beta$ & $\mathrm{p}$ \\
\hline Disease severity & 0.52 & $<.001$ & 0.26 & $<.001$ & 0.28 & $<.001$ & 0.30 & $<.001$ & 0.23 & .009 \\
\hline Age & -0.34 & $<.001$ & -0.12 & .20 & -0.10 & .28 & -0.15 & .11 & -0.12 & .23 \\
\hline IP thickness & - & - & 0.46 & $<.001$ & 0.46 & $<.001$ & 0.46 & $<.001$ & 0.47 & $<.001$ \\
\hline IP FTP & - & - & 0.19 & .08 & 0.16 & .14 & 0.45 & .006 & 0.17 & .16 \\
\hline MTL volume & - & - & - & - & -0.07 & .37 & - & - & - & - \\
\hline funcROI FTP & - & - & - & - & - & - & -0.34 & .02 & - & - \\
\hline funcROI PIB & - & - & - & - & - & - & 0.01 & .88 & - & - \\
\hline APOE $\varepsilon 4$ & - & - & - & - & - & - & - & - & -0.12 & .42 \\
\hline $\mathbf{R}^{2}\left(\Delta \mathbf{R}^{2}\right)$ & \multicolumn{2}{|c|}{0.44 (Ref) } & \multicolumn{2}{|c|}{$0.65(0.21)$} & \multicolumn{2}{|c|}{$0.65(0.21)$} & \multicolumn{2}{|c|}{$0.67(0.23)$} & \multicolumn{2}{|c|}{$0.65(0.22)$} \\
\hline $\mathrm{BIC}\left(\Delta \mathrm{BIC}_{0}\right)$ & \multicolumn{2}{|c|}{-96 (Ref) } & \multicolumn{2}{|c|}{$-126(-30)$} & \multicolumn{2}{|c|}{$-123(-27)$} & \multicolumn{2}{|c|}{$-124(-28)$} & \multicolumn{2}{|c|}{$-120(-24)$} \\
\hline
\end{tabular}

Table 2. Linear regression models testing all hypothesized factors, UCSF.

Analyses are run within the UCSF cohort and within region, where FDG in either RSC (A) or IP (B) is the singular dependent variable. Local cortical thickness and FTP are included in all hypothesis-testing models due to their robust associations with FDG in previous correlation 
medRxiv preprint doi: https://doi.org/10.1101/2021.03.08.21252999; this version posted March 12, 2021. The copyright holder for this preprint (which was not certified by peer review) is the author/funder, who has granted medRxiv a license to display the preprint in perpetuity. It is made available under a CC-BY-NC-ND 4.0 International license.

analyses. Models including APOE $\varepsilon 4$ are run within a smaller sample $(\mathrm{n}=76)$, and the reference levels for $\mathrm{R}^{2}$ and $\mathrm{BIC}$ are modified accordingly. MTL volume was divided by total intracranial volume prior to analyses. $\beta=$ standardized estimate; $\mathrm{BIC}=$ Bayesian Information Criteria. 
medRxiv preprint doi: https://doi.org/10.1101/2021.03.08.21252999; this version posted March 12, 2021. The copyright holder for this preprint (which was not certified by peer review) is the author/funder, who has granted medRxiv a license to display the preprint in perpetuity.

It is made available under a CC-BY-NC-ND 4.0 International license.

\begin{tabular}{|c|c|c|c|c|c|c|c|c|c|c|}
\hline \multirow{2}{*}{$\begin{array}{l}\text { A. RSC FDG } \\
\text { Predictors }\end{array}$} & \multicolumn{2}{|c|}{ Model 0} & \multicolumn{2}{|c|}{ Model 1} & \multicolumn{2}{|c|}{ Model 2} & \multicolumn{2}{|c|}{ Model 3} & \multicolumn{2}{|c|}{ Model 4} \\
\hline & $\beta$ & $\mathrm{p}$ & $\beta$ & $\mathrm{p}$ & $\beta$ & $\mathrm{p}$ & $\beta$ & $\mathrm{p}$ & $\beta$ & $\mathrm{p}$ \\
\hline Disease severity & 0.48 & $<.001$ & 0.32 & $<.001$ & 0.23 & .007 & 0.26 & .02 & 0.29 & $<.001$ \\
\hline Age & 0.05 & .47 & 0.19 & .02 & 0.13 & .11 & 0.27 & .03 & 0.28 & .003 \\
\hline RSC thickness & - & - & 0.24 & .001 & 0.23 & .001 & 0.20 & .04 & 0.26 & .001 \\
\hline RSC FTP & - & - & 0.25 & .005 & 0.22 & .01 & 0.34 & .13 & 0.27 & .005 \\
\hline MTL volume & - & - & - & - & 0.22 & .008 & - & - & - & - \\
\hline funcROI FTP & - & - & - & - & - & - & -0.09 & .65 & - & - \\
\hline funcROI FBP & - & - & - & - & - & - & 0.00 & .96 & - & - \\
\hline$A P O E \varepsilon 4$ & - & - & - & - & - & - & - & - & 0.20 & .23 \\
\hline $\mathbf{R}^{2}\left(\Delta \mathbf{R}^{2}\right)$ & \multicolumn{2}{|c|}{0.24 (Ref) } & \multicolumn{2}{|c|}{$0.33(0.09)$} & \multicolumn{2}{|c|}{$0.37(0.13)$} & \multicolumn{2}{|c|}{$0.28(0.09)$} & \multicolumn{2}{|c|}{$0.36(0.13)$} \\
\hline $\operatorname{BIC}\left(\Delta \mathrm{BIC}_{0}\right)$ & \multicolumn{2}{|c|}{-121 (Ref) } & \multicolumn{2}{|c|}{$-130(-9)$} & \multicolumn{2}{|c|}{$-133(-12)$} & \multicolumn{2}{|c|}{$-113(+8)$} & \multicolumn{2}{|c|}{$-129(-8)$} \\
\hline
\end{tabular}

\begin{tabular}{|c|c|c|c|c|c|c|c|c|c|c|}
\hline \multirow{2}{*}{$\begin{array}{l}\text { B. IP FDG } \\
\text { Predictors }\end{array}$} & \multicolumn{2}{|c|}{ Model 0} & \multicolumn{2}{|c|}{ Model 1} & \multicolumn{2}{|c|}{ Model 2} & \multicolumn{2}{|c|}{ Model 3} & \multicolumn{2}{|c|}{ Model 4} \\
\hline & $\beta$ & $\mathrm{p}$ & $\beta$ & $p$ & $\beta$ & $\mathrm{p}$ & $\beta$ & $p$ & $\beta$ & $p$ \\
\hline Disease severity & 0.47 & $<.001$ & 0.29 & $<.001$ & 0.32 & $<.001$ & 0.28 & .02 & 0.28 & .001 \\
\hline Age & -0.05 & .48 & 0.12 & .17 & 0.14 & .12 & 0.16 & .20 & 0.16 & .08 \\
\hline IP thickness & - & - & 0.16 & .04 & 0.16 & .04 & 0.10 & .34 & 0.15 & .07 \\
\hline IP FTP & - & - & 0.32 & .001 & 0.33 & $<.001$ & 0.34 & .26 & 0.36 & $<.001$ \\
\hline MTL volume & - & - & - & - & -0.07 & .38 & - & - & - & - \\
\hline funcROI FTP & - & - & - & - & - & - & -0.05 & .86 & - & - \\
\hline funcROI FBP & - & - & - & - & - & - & 0.01 & .90 & - & - \\
\hline$A P O E \varepsilon 4$ & - & - & - & - & - & - & - & - & 0.19 & .24 \\
\hline $\mathbf{R}^{2}\left(\Delta \mathbf{R}^{2}\right)$ & \multicolumn{2}{|c|}{0.22 (Ref) } & \multicolumn{2}{|c|}{$0.33(0.11)$} & \multicolumn{2}{|c|}{$0.33(0.11)$} & \multicolumn{2}{|c|}{$0.26(0.07)$} & \multicolumn{2}{|c|}{$0.37(0.13)$} \\
\hline $\operatorname{BIC}\left(\Delta B \mid C_{0}\right)$ & \multicolumn{2}{|c|}{-134 (Ref) } & \multicolumn{2}{|c|}{$-146(-12)$} & \multicolumn{2}{|c|}{$-141(-7)$} & \multicolumn{2}{|c|}{$-125(+9)$} & \multicolumn{2}{|c|}{$-143(-9)$} \\
\hline
\end{tabular}

Table 3. Linear regression models testing all hypothesized factors, ADNI.

Analyses are run within the ADNI cohort and within region, where FDG in either RSC (A) or IP (B) is the singular dependent variable. Local cortical thickness and FTP are included in all hypothesis-testing models due to their robust associations with FDG in previous correlation 
medRxiv preprint doi: https://doi.org/10.1101/2021.03.08.21252999; this version posted March 12, 2021. The copyright holder for this preprint (which was not certified by peer review) is the author/funder, who has granted medRxiv a license to display the preprint in perpetuity. It is made available under a CC-BY-NC-ND 4.0 International license.

analyses. Models including funcROI FBP or $A P O E \varepsilon 4$ are run within smaller samples ( $\mathrm{n}=87$ for Model 3 and $\mathrm{n}=124$ for Model 4 ), and the reference levels for $\mathrm{R}^{2}$ and BIC are modified accordingly. MTL volume was divided by total intracranial volume prior to analyses. $\beta=$ standardized estimate; $\mathrm{BIC}=$ Bayesian Information Criteria. 

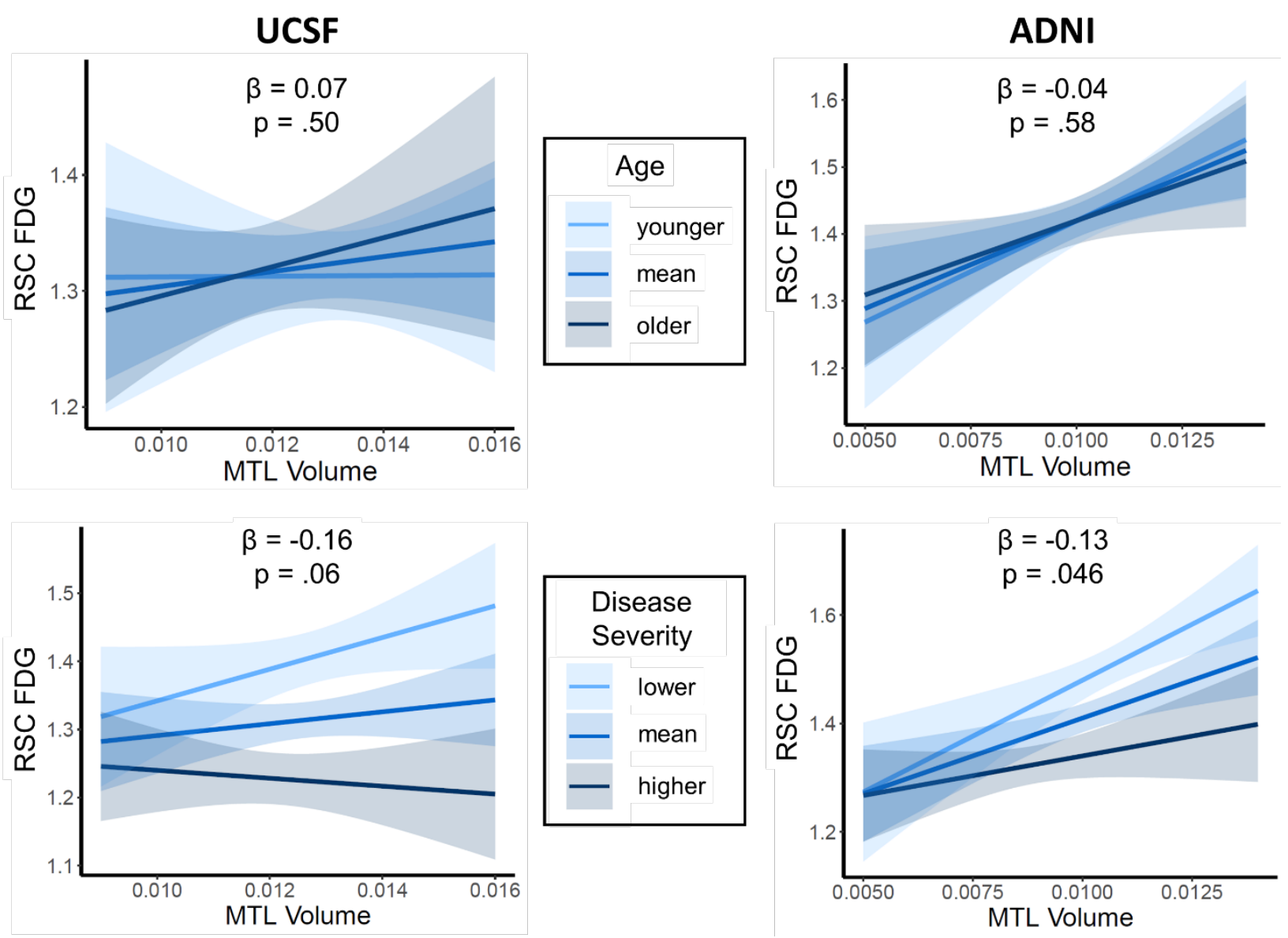

Figure 4. Interaction analyses between MTL volume and age or disease severity in predicting RSC hypometabolism. Each plot represents a separate model. Models include age, disease severity, MTL volume (divided by total intracranial volume), and the interaction term between MTL volume and age or disease severity. Reported $p$ and $\beta$ (standardized estimate) values refer to the interaction term. Bins refer to mean \pm 1 standard deviation of within-cohort age or disease severity. For age, these values correspond to 55,65 , and 74 years for UCSF; or 67,75 , and 83 years for ADNI. For disease severity, bins correspond to CDR-SB/MMSE values of 2.0/27, 4.0/20; and 6.0/14 for UCSF; or $0.5 / 29,1.5 / 24$, and $3.5 / 20$ for ADNI. 